IZA DP No. 9852

Labor Market Networks and Recovery from Mass Layoffs Before, During, and After the Great Recession

Judith K. Hellerstein

Mark J. Kutzbach

David Neumark

March 2016 


\title{
Labor Market Networks and Recovery from Mass Layoffs Before, During, and After the Great Recession
}

\author{
Judith K. Hellerstein \\ University of Maryland and NBER \\ Mark J. Kutzbach \\ U.S. Census Bureau \\ David Neumark \\ University of California, Irvine, NBER and IZA
}

Discussion Paper No. 9852

March 2016

IZA

P.O. Box 7240

53072 Bonn

Germany

Phone: +49-228-3894-0

Fax: +49-228-3894-180

E-mail: iza@iza.org

Any opinions expressed here are those of the author(s) and not those of IZA. Research published in this series may include views on policy, but the institute itself takes no institutional policy positions. The IZA research network is committed to the IZA Guiding Principles of Research Integrity.

The Institute for the Study of Labor (IZA) in Bonn is a local and virtual international research center and a place of communication between science, politics and business. IZA is an independent nonprofit organization supported by Deutsche Post Foundation. The center is associated with the University of Bonn and offers a stimulating research environment through its international network, workshops and conferences, data service, project support, research visits and doctoral program. IZA engages in (i) original and internationally competitive research in all fields of labor economics, (ii) development of policy concepts, and (iii) dissemination of research results and concepts to the interested public.

IZA Discussion Papers often represent preliminary work and are circulated to encourage discussion. Citation of such a paper should account for its provisional character. A revised version may be available directly from the author. 


\title{
ABSTRACT \\ Labor Market Networks and Recovery from Mass Layoffs Before, During, and After the Great Recession*
}

\begin{abstract}
We measure the impact of labor market referral networks defined by residential neighborhoods on re-employment following mass layoffs. Because networks can only be effective when hiring is occurring, we focus on a measure of the strength of the labor market network that includes not only the number of employed neighbors of a laid off worker, but also the gross hiring rate at that person's neighbors' workplaces. We provide additional evidence from two alternative measures of network strength that try to disentangle the mechanism by which networks operate - either by conveying information to job seekers about vacancies or conveying information to hiring employers about potential hires. Our evidence indicates that stronger local labor market networks are linked not just to more rapid re-employment following mass layoffs but to re-employment specifically at neighbors' employers. We also find evidence suggesting that this effect is stronger via network connections that convey information to job seekers about vacancies. Finally, we find evidence that the effects of networks for displaced workers declined during the Great Recession relative to prior or subsequent years.
\end{abstract}

JEL Classification: J63, J64

Keywords: networks, displacement, re-employment

Corresponding author:

David Neumark

Department of Economics

3151 Social Science Plaza

University of California, Irvine

Irvine, CA 92697

USA

E-mail: dneumark@uci.edu

\footnotetext{
* We thank seminar/conference participants at the Institute of Poverty Research, the Israel Real Estate and Urban Economics Symposium, the Urban Economics Association, Tufts, Uppsala University, the University of Washington, the All-California Labor Economics Conference, the NBER Urban Economics Summer Institute, and the BLS-Census Workshop, and Bob Edelstein, Erika McEntarfer, Lars Vilhuber, and Maury Gittleman for helpful comments. Any opinions and conclusions expressed herein are those of the authors and do not necessarily represent the views of the U.S. Census Bureau. All results have been reviewed to ensure that no confidential information is disclosed. This research was supported by a grant from the Russell Sage Foundation; the views expressed are our own.
} 


\section{Introduction}

During the Great Recession and its immediate aftermath, the U.S. labor market experienced massive job losses not seen in at least three decades. We know that involuntary job displacement has longterm adverse consequences on employment and earnings (e.g. Jacobsen et al., 1993, hereafter JLS; Davis and von Wachter, 2011), and even on mortality (Sullivan and von Wachter, 2009). Because of this, it is important to identify factors that can help facilitate the re-employment of displaced workers.

In this paper, we explore the role of labor market networks in the re-employment process. We focus on labor market networks defined by residential neighborhoods, based on prior research indicating that such networks play an important role in matching workers to employers (Bayer et al., 2008; Hellerstein et al., 2011 (HNM) and $2014(\mathrm{HKN}))$. Because networks can only be productive when hiring is occurring, we focus on a measure of the strength of the labor market network that incorporates not only the number of neighbors of a laid off worker, but also the gross hiring rate at that person's neighbors' workplaces. In particular, we test the hypothesis that strong labor market networks formed by residential neighbors help in the labor market recovery of displaced workers by facilitating faster re-employment overall, and reemployment specifically with hiring employers where neighbors in the network already are working.

In addition to just examining the average effect of network strength in facilitating labor market recovery for displaced workers, we explore differences in the effects of network strength on the employment recovery of displaced workers in the periods prior to, during, and coming out of the Great Recession, asking whether positive effects of network strength, if they exist, are stronger or weaker during the recession. ${ }^{1,2}$ It is not clear that economic theory makes any strong prediction about the answer to this question. But the press was replete with anecdotal evidence (and advice) on the importance of network connections in finding jobs during the Great Recession. ${ }^{3}$ Of course, such anecdotes prove nothing.

\footnotetext{
${ }^{1}$ For the purposes of this paper we treat the Great Recession period as extending into 2010 when the recession had formally ended but unemployment was still extremely high.

${ }^{2}$ As we make clear below, our measure of network strength not only captures how many members are in a displaced worker's network, but also the potential connections these members have to existing vacancies.

${ }^{3}$ For example: http://money.cnn.com/2009/03/27/news/economy/yang_jobhunters.fortune/index.htm?utm_source=feedburner\&utm medium $=$ feed\&utm_campaign $=$ Feed $\% 3 \mathrm{~A}+$ rss\%2Fmoney_latest $+($ Latest + News $)$;
} 
Networks may be more productive for displaced workers when the economy is not in recession (or its aftermath), but the media are less likely to focus on how workers found jobs in such periods. Moreover, there were contradictory stories claiming that network hiring became more important as the economy recovered, while suggesting that networks were less important during the recession because network connections were "severed."

In empirical tests of the importance of labor market networks, it is a challenge to identify exogenous sources of variation in networks because individual-level unobservables may be correlated with both the outcomes studied (e.g., employment generally) and with sorting into networks. In our view, we generate particularly compelling evidence on the roles of labor market networks for four reasons. First, we study workers who lost jobs because of mass layoffs that are quite likely exogenous with respect to other characteristics of workers that might be correlated with network measures. Second, we use observational data derived from administrative records of displaced workers and their neighbors, and so our results are broadly representative of an important population of workers. Third, because of the matched employeremployee data we have, we are able to estimate highly-saturated models that include layoff-specific fixed effects. This allows us to identify the effects of networks using only variation within a given mass layoff in the strength of networks in the neighborhoods across which laid off workers live. We argue that this withinmass layoff variation in network strength, especially when coupled with other controls for local labor market strength, is very unlikely to be correlated with remaining unobserved determinants of reemployment probabilities of the workers themselves. And fourth, for those displaced workers who are reemployed, we observe whether re-employment occurred specifically at the employer of a neighbor, as most network models would suggest. By restricting our sample to only those displaced workers who are subsequently re-employed, and by examining whether network strength is related to the likelihood that they are re-employed alongside a neighbor, we effectively eliminate unobservables that are correlated with network strength and that also determine re-employment itself. In addition, finding that stronger labor

http://abcnews.go.com/Business/jobs-outlook-college-graduates/story?id=16345862;

http://www.jibberjobber.com/blog/2008/10/07/how-to-find-a-job-in-a-recession/ (all viewed May 30, 2014).

${ }^{4}$ For example: http://www.nytimes.com/2013/01/28/business/employers-increasingly-rely-on-internal-referrals-inhiring.html?_r=0 (viewed May 14, 2014). 
market networks increase the probability of re-employment at the employers of employed network members is an especially compelling result given that it is the outcome predicted by leading theories of the exact mechanism(s) by which labor market networks operate.

To briefly summarize our evidence, we find that stronger residence-based labor market networks not only lead to more rapid re-employment for displaced workers, but that they facilitate re-employment by matching the displaced workers to vacancies at neighbor's employers - just as theory would suggest. These effects are substantially larger for low earners than for high earners, as might be expected given that the relevant labor markets for low-skilled workers tend to be more local. Although our results hold true throughout our sample period, the effects of local labor market network strength on re-employment were weaker during the Great Recession, principally because fewer network members were employed and their employers were doing less hiring.

\section{Motivation and Previous Research}

Standard approaches to the search behavior of unemployed individuals (e.g., Ham and Rhea, 1987) generally model the probability that an unemployed worker becomes re-employed as a function of the unemployment rate, the vacancy rate, the worker's reservation wage, and the worker's preferences for nonwork activity. In models of spatial mismatch such as Kain (1968) (or more nuanced versions, such as Hellerstein et al., 2008), the probability of finding employment is also a function of job accessibility, which itself is related to factors such as commuting costs and information about vacancies in very local labor markets such as neighborhoods.

Theoretical models of labor market networks expand on these standard models by assuming that there is imperfect information that hinders the search behavior of unemployed workers and/or firms, and that information flows through networks. These models generally fall into one of two categories that describe the information imperfections and how they are mitigated by networks. In models such as CalvóArmengol and Jackson (2007) and Ioannides and Soetevent (2006), unemployed workers do not have full information about job vacancies. These job searchers can learn about job vacancies either directly from employers or indirectly via employed individuals among their network contacts. The probability that an 
unemployed worker learns of a job vacancy is generally positively related to the size of his/her network, and negatively related to the unemployment rate in his/her local labor market. In equilibrium, better connected job searchers are more likely to find employment and to have higher wages.

In the other class of network models, the information imperfection is on the employer side, where employers do not have full information about the quality of job applicants or the job match that would arise if the applicant were hired. Specifically, in Montgomery (1991), firms learn about a potential worker's ability if the firm employs individuals from the potential worker's network. In equilibrium, individuals are more likely to receive and accept wage offers from businesses that employ others in their network, creating stratification across employers on the basis of these networks. ${ }^{5}$

These two classes of models both imply that an unemployed individual will have better labor market outcomes if he or she searches for work in a local labor market (or markets) with a high vacancy rate(s) and a low unemployment rate(s), and if he or she has many network contacts that either can pass along information on specific job vacancies to the unemployed individual and/or that can pass along to an employer information about the productivity of the unemployed individual. ${ }^{6}$

Estimating models of job search behavior that incorporate all of these features is challenging due to data constraints in measuring key variables such as the strength and nature of labor market networks, the size and scope of local labor markets, characteristics of individuals that affect their reservation wage, and the availability and accessibility of job vacancies. Partially as a result, when it comes to research on the importance of labor market networks, there is a large, earlier body of empirical research that documents the importance of informal contacts in finding jobs, but which does not identify with whom workers are networked (Ioannides and Datcher Loury, 2004). However, recent empirical research suggests that labor market networks based on residential communities or neighborhoods are important. Using confidential Long-Form 2000 Census data (in Boston), Bayer et al. (2008) show that two individuals who live on the same Census block are about one-third more likely to work on the same block than are two individuals who

\footnotetext{
${ }^{5}$ Jackson (2008, Chapter 10) provides a transparent discussion and comparison of these models.

${ }^{6}$ Working with network members does not always lead to higher productivity, however. For example, Bandiera et al. (2005) show that working with peers can lead to lower productivity when an individual's compensation creates negative externalities for peers.
} 
live in the same block group but not on the same block. (The latter may be alike, but are less likely to be networked.)

HNM take this further by trying to capture connections between neighbors who work at the same business establishment, and not just in the same location, consistent with the hypotheses that labor market networks mitigate employers' lack of information about workers or that these networks provide job searchers with information on vacancies at those businesses. HNM develop a measure of the extent to which employees of a business establishment come disproportionately from people who live in the same neighborhood (defined as a Census tract), relative to the residential locations of other employees working in the same Census tract but in different establishments - termed "network isolation" to capture how much workers from the same neighborhood are isolated or segregated from workers from other nearby neighborhoods. This concept parallels the well-known and influential work by Granovetter (1974), extending beyond a very narrow (and by now old) case study to a very large national sample. HNM calculate network isolation using information on workers reporting to the 2000 Decennial Census Long Form who are matched to administrative information on establishments. The results indicate that residencebased labor market networks at the level of a Census tract appear to be quite important in influencing where people work, especially for less-educated workers and immigrants.

In this paper we turn our attention to the effects of residence-based labor market networks in helping non-employed workers in general, and displaced workers in particular, find work. This issue is especially important within the context of the large job losses that accompanied the Great Recession and the ensuing high rates of unemployment and low rates of labor force participation, so our analysis estimates network effects on re-employment for workers displaced right before, during, and just after the Great Recession.

There is some related work on labor market networks and recovery from displacement. This work uses other dimensions of labor market networks, emphasizing that network connections that may be productive in the labor market - whether or not in the context of displacement - need not arise only through connections between neighbors. Glitz (2014) suggests that network connections to co-workers (or former 
co-workers) may be more important because those co-workers should know more about a person's work abilities, and also should be likely to know each other (although that may not be true in larger firms). Using German data, he finds that displaced workers within the same "origin" establishment have a higher probability of re-employment when the employment rate among former co-workers is higher, using exogenous variation (as an instrumental variable) in that employment rate driven by mass layoffs among those co-workers. Saygin et al. (2014) report similar results for Austria, although without the advantage of the mass layoff instrumental variable. They also find some evidence that displaced workers are more likely to become re-employed at a firm that employs former co-workers of the displaced worker. ${ }^{7}$ And Cingano and Rosolia (2012) present related evidence for Italy, finding that for networks defined by "co-displaced" workers, employment (re-employment) of other co-displaced workers in the network reduces unemployment duration.

However, these other recent papers focus on network links to former co-workers, whereas we study residential labor market networks. Without in any way implying that network links among co-workers are not operative or important, the "urban" flavor of residence-based labor markets is potentially important for at least two reasons. First, if there are network links among neighborhood residents, policymakers may be able to exploit the "multipliers" that networks can generate to enhance the impact of place-based policies, but conversely it is also possible that place-based policies that fail to generate jobs among residents of those places can, for the same reason, cause those policies to underperform in generating employment among local residents (see the discussion in Neumark and Simpson, 2015). And second, residence-based labor markets can help explain concentrations of low employment and poverty in particular local areas, and can also - if these networks are racially- or ethnically-stratified - help explain pockets of poor economic performance in minority, segregated neighborhoods. At the same time, paralleling the argument with respect to place-based policies, such networks may provide scope for enhanced efforts to increase employment in these areas. ${ }^{8}$

\footnotetext{
${ }^{7}$ Saygin et al. (2014) suggest that this implies that these former co-workers are referring the displaced worker to their employer, à la Montgomery (1991) and Simon and Warner (1992), but this evidence is equally consistent with former co-workers simply providing information about the availability of jobs at their firm.

${ }^{8}$ Hellerstein and Neumark (2012) discuss this in the context of the Jobs-Plus experiment.
} 


\section{Network Measures and Analysis}

Consider a sample of workers who lose their jobs as part of the huge number of layoffs that accompanied the Great Recession. How quickly are these displaced workers able to find jobs? And how does the strength of their neighborhood networks affect post-layoff re-employment?

Thinking of theoretical models of search and of networks, a displaced worker's probability of finding work in a given period of time will be a positive function of the vacancy rate in their local labor market, a negative function of the unemployment rate in their local labor market, a negative function of their reservation wage, a negative function of the length of time the person has been unemployed (assuming there is negative duration dependence, as suggested in recent work by Kroft et al., 2013), and of course will also be related to preferences for non-work activities like leisure. In addition, depending on the nature of imperfect information in the labor market, a displaced worker's probability of finding work may well be a function of the network contacts they have and whether they know about job vacancies.

We consider how the re-employment probability of a displaced worker is affected by the strength of his or her residential labor market network, examining both re-employment generally and reemployment specifically at a neighbor's workplace. ${ }^{9}$ We limit our analysis to examining outcomes in the quarter following displacement, partially for simplicity, but more so because workers with long durations of unemployment prior to the Great Recession were likely much more negatively selected than those with long durations during the Great Recession, whereas workers with short durations of unemployment were likely more similar in the two periods, so comparisons of network effects for them before and during (and after) the Great Recession are more valid.

We operationalize the strength of an unemployed worker's network by developing a measure of the

\footnotetext{
${ }^{9}$ We do not report results for earnings as an outcome in our network analysis for a number of reasons. First, in HKN we found strong positive effects of networks on reducing turnover for employed workers, but less robust results for wages. Although network models predict better job matches that should lead to higher wages, the effect could go in the other direction either because people prefer to work with their neighbors, or because worker reliance on networks may signal high search costs enabling employers to offer lower wages. Second, in the context of the Great Recession's historically high unemployment rates and low labor force participation, re-employment for displaced workers is the first-order outcome of interest. Third, and relatedly, as we show below, the recovery of earnings in our sample is itself driven primarily by re-employment. As a result, although we did explore the impact of networks on the postdisplacement earnings of displaced workers, these results (available upon request) are driven by re-employment.
} 
strength of residence-based hiring networks at the level of the Census tract of residence. ${ }^{10} \mathrm{We}$ then empirically examine whether and how this measure of network strength affects post-displacement employment, conditional on an extremely large set of worker, employer, neighborhood, and job-related covariates that we are able to use given the considerable detail and size of the LEHD dataset.

In order to explain our network strength measure and the data in the LEHD from which they come, consider the hypothetical case of one specific job searcher who is searching for a job after being displaced from his/her employer in a mass layoff in a given quarter. Given the detailed longitudinal nature of the LEHD, we observe the displaced worker's pre-displacement earnings, as well as his/her post-displacement earnings (if any). We also have an indicator for the establishment from which the job searcher was displaced, as well as some demographic information about him/her. Critically, we observe the Census tract in which he or she lives. We also can observe various characteristics of that Census tract, most importantly the number of adult neighbors that the job searcher has (defined as residents of that Census tract). For the each of those neighbors, we know whether the neighbor is employed in the quarter following the job searcher's displacement. In addition, for each employed neighbor, we observe the establishment in which they work, as well as important characteristics of those establishments, including, importantly, whether the establishments are observed to make any gross hires in that post-displacement quarter.

We term our core network measure as the "active employer network" measure, denoted $A E N .{ }^{11}$ This measure is motivated by the fact that our job searcher's employed neighbors can transmit information about vacancies at the establishments where they work, if there are vacancies. Recall that for each of the job searcher's neighbors, we observe not only whether he or she works, but also where he or she works (if employed). For each establishment at which a neighbor works, we therefore can calculate the gross hiring rate at that establishment in the quarter following the job searcher's displacement (defined as the gross number of new hires divided by the number of employees in the quarter). Using a measure of the gross hiring rate rather than the absolute number of gross hires is a scaling measure that is meant to capture competition among job seekers for vacancies. That is, our job searcher's neighbor may have information on

\footnotetext{
${ }^{10}$ Most of our analysis focuses on one measure; we consider some alternative measures later.

11 "Employer" throughout refers to the establishment of employment.
} 
vacancies at his or her establishment to transmit to our job searcher, but that information is also transmitted by employees who live in other Census tracts back to the job searchers in their own Census tracts. In other words, a large number of gross hires at a neighbor's employer does not necessarily imply that our job searcher learns about more potentially productive vacancies than from a small number of gross hires at a small employer. We then calculate the average of this gross hiring rate across all of our job searcher's neighbors, where his/her unemployed neighbors contribute zeroes to this average. Thus, the "active employer network" measure for our job searcher is defined as:

$$
A E N=\frac{1}{N} \sum_{i}^{N} I_{i} \cdot \frac{H_{i e}}{L_{i e}}
$$

where $N$ is the number of neighbors in our job searcher's Census tract at the time of his/her displacement, $I_{i}$ is an indicator for whether neighbor $i$ is employed, and $\frac{H_{i e}}{L_{i e}}$ is the ratio of new hires at the employer $e$ of neighbor $i$ in the first quarter following our job searcher's displacement, divided by the count of employees at that employer in the beginning of that quarter. ${ }^{12}$ Note that the neighbors who are not employed contribute zeroes to the measure; $\frac{H_{i e}}{L_{i e}}$ is undefined for these cases, but we have not introduced additional notation since this expression is multiplied by zero in these cases. We take the average across all of our job searcher's neighbors, $N$, rather than just over employed neighbors, to reflect the fact that when more neighbors are job searchers as well, the probability is lower that our job searcher will obtain productive information on vacancies from his or her neighbors, either because vacancy information is like a private good passed along by employed workers to only a subset (of perhaps one) of the job searchers in their network, or because our job searcher will have to compete with his/her neighbors when applying to job vacancies that are accessed through the neighborhood network.

Note also that if multiple neighbors work at the same employer, each of these contacts contributes to $A E N$. If we actually knew that every neighbor was in our job searcher's network, this might lead to

\footnotetext{
${ }^{12}$ The "active" part of the name references the fact that this measure only counts connections where there is gross hiring occurring.
} 
double counting, if the neighbors were giving the job searcher redundant information about vacancies. However, it is more likely that our job searcher learns of labor market information only from a subset of neighbors, in which case more neighbors working at an employer who is doing hiring makes it more likely that information about those vacancies reaches our job searcher. In addition, if there is some noise in the vacancy information that a given neighbor transmits, that noise can diminish relative to the signal if vacancy information is transmitted by multiple neighbors (and the noise is not perfectly correlated across them). For these reasons, we allow the network measure $A E N$ to increase in the number of neighbors working at the same employer.

The active employer network measure captures the notion that a job searcher's employed neighbors have information about vacancies in their establishments that can be transmitted. But the neighbors may also have more general information about vacancies in establishments near to their own, rather than just in their own establishments. ${ }^{13}$ We therefore construct a measure corresponding to $A E N$ that can capture information on vacancies in a geographic area, paralleling $A E N$ but averaging across hiring rates in all the establishments in the tracts where neighbors work, rather than just at the specific establishments where they work. Note that such a measure may alternatively or additionally capture the general strength of demand conditions in the local labor market, because neighbors' workplaces likely represent the set of locations with economic opportunities that are easily accessible by transportation. ${ }^{14}$ Because of the potential dual role of this measure, we refer to it as the "active tract control" $(A T C)$, defined as:

$$
A T C=\frac{1}{N} \sum_{i}^{N} I_{i} \cdot \frac{H_{i w}}{L_{i w}}
$$

where the hiring rate is measured in the Census tract $w$ in which worker $i$ works, rather than just at their employer. ${ }^{15}$ Because $A T C$ can pick up network effects, we report estimates of its effects along with those of

\footnotetext{
${ }^{13}$ This is the conceptualization of networks used in Bayer et al. (2008), although they use the word "referrals" in the context of co-residents providing information to each other about jobs near where they work (p. 1152).

${ }^{14}$ In contrast, Bayer et al., (2008) are able to control for the strength of the local labor market by treating neighbors as those who live only on the same Census block in measuring network ties, and treating correlated outcomes among those who live in the same Census tract as (potentially) measuring local labor demand, job access, etc.

${ }^{15}$ The use of "active" in the name reminds the reader that the construction parallels $A E N$.
} 
our key network measure $A E N$, although we again emphasize that it can simply be thought of a control for the strength of the local labor market.

\section{Data}

The core dataset from which the samples we study are extracted is the Census Bureau's LEHD Infrastructure files. ${ }^{16}$ The files consist of a frame of jobs produced from state unemployment insurance reporting systems, augmented with information on worker and employer characteristics. The state data cover the universe of wage and salary workers in the private sector as well as state and local government workers, but do not include federal workers or earnings through self-employment. States provide the Census Bureau with two quarterly files. The earnings history file lists the quarterly earnings accruing to a worker from an employer. The employer file includes information on industry, ownership, size, and location of employer establishments. In order to disaggregate employment statistics by worker characteristics including age, sex, race, and ethnicity, and by home location, LEHD supplements the jobs data with demographic variables derived from the Social Security Administration's NUMIDENT file and the 2000 Census, as well as place-of-residence from federal administrative records. The LEHD Infrastructure files use unique person and employer identifiers to merge worker and employer data.

We use the LEHD Infrastructure files to identify a set of workers separating from jobs in mass displacement events, to measure the workers' pre-displacement characteristics and post-displacement labor market outcomes, and to characterize labor market networks in the neighborhood in which a displaced worker resides. We begin with an extract of 1.7 billion jobs, or spells of earnings from an employer, held from 2004 through 2014 at employers located in 49 states. ${ }^{17}$

From these data, we identify 136 million workers separated from their highest earning (dominant) job from 2005 through 2012, as defined here. We observe a job separation in the LEHD as the end of a stream of quarterly earnings of a worker from an employer, and assume that the separation occurred at some time in the final quarter of earnings. Our definition is parallel to the Quarterly Workforce Indicators

\footnotetext{
${ }^{16}$ See (Abowd et al., 2009) for a summary of the various components of the LEHD Infrastructure files.

${ }^{17}$ We include all states except for Massachusetts, which (along with the District of Columbia) did not begin submitting data to the Census Bureau until after 2005.
} 
variable "Separations, Beginning-of-Quarter Employed," except that we also restrict attention to a set of attached workers, defined as having been employed at a firm for four consecutive quarters before the separation, and we further require that the separated worker not return to the employer in the two years following the separation. ${ }^{18}$ Last, we require that the separation was from the worker's main (i.e., highestearning) job in the quarter prior to displacement, with the idea that the loss of a main job is likely to lead the worker to search for a new job. Note that some of the separated workers may hold a secondary job, and maintain that job following the separation.

Although all job searchers clearly can potentially activate labor market networks as part of their search, we restrict attention to the outcomes of non-employed individuals who have experienced mass layoffs. We do this in order to focus on workers who are exogenously displaced from their jobs due to labor force contractions (and thus not due to individual-specific unobservables that may affect post-displacement labor market outcomes and also may be correlated with our network measures). This is standard in the literature on displaced workers (e.g., JLS, 1993; Davis and Von Wachter, 2011). Consistent with past work on displaced workers, we define mass layoffs based on whether establishments had a certain initial employment size that subsequently dropped by a minimum percentage. In particular, we define a mass layoff based on an initial employment level of at least 25 workers, which subsequently fell by at least 30 percent over a period of one year (four quarters) during which we observe a worker leaving the establishment. For this sample, 78.5 percent of separations were at employers with 25 or more workers in the previous year, and 15.2 also had a drop of 30 percent or more that was not simply a restructuring. ${ }^{19}$ With this definition, we identify 20.7 million workers displaced from 2005 to 2012 .

We apply several additional restrictions to the set of displaced workers based on data availability constraints and suitability for our research focus. We are able to assign a Census tract of residence in the

\footnotetext{
${ }^{18}$ We require that displaced workers have no earnings at the downsizing employer for eight subsequent quarters. Included in that definition of employer are any other employers that the LEHD has linked to the downsizing employer using the Successor Predecessor File. For more on the QWI variable definitions, see: http://lehd.ces.census.gov/doc/QWI_101.pdf.

${ }^{19}$ The Successor Predecessor File tracks worker flows across employers to identify spurious separations.
} 
year of displacement in one of the 49 states in our analysis to 89.1 percent of the sample. ${ }^{20}$ From among these locations, we require that the Census tract is entirely classified as urban and has at least 100 resident workers, which restricts attention to more densely populated areas in which neighbors are more likely to interact. ${ }^{21}$ We drop a further 6.2 percent of the remaining workers who are not between 19 and 64 years old in the quarter in which they separated.

From the resulting sample of 10.2 million displacements, we retain those who had predisplacement annual earnings from all jobs of between $\$ 5,000$ and $\$ 100,000$ (in 2010Q1\$), for two reasons. ${ }^{22}$ First, the relevant labor market and network contacts of especially high earners are likely quite different from those of lower earners; in particular high earners are likely to have networks and to engage in job search in a more national labor market and so residential network contacts are likely much less important. Second, the lower restriction excludes workers who, although they held a job for at least a year, were more likely to be a secondary earner or dependent, or otherwise not highly attached to the wage and salary labor market. The upper bound drops 7.7 percent of workers and the lower bound drops 2.2 percent, resulting in a final estimation sample of 9.2 million displaced workers.

Table 1 provides mean characteristics of our worker sample, including the variables we will use as controls in the regression models described in the next section. We link in the neighborhood (Census tract) poverty rate (from the 2000 Decennial Census), as well as numerous other tract characteristics pertaining to demography, education, and residential mobility, which control for longer-term labor market conditions of the worker's place of residence and characteristics of the worker's neighbors. We describe the construction of the quarterly employment rate below. Age is calculated for the quarter of displacement, and industry

\footnotetext{
${ }^{20}$ We use the Composite Person Record, an annual file built from federal administrative data on residential addresses that contributes to the LEHD Infrastructure files.

${ }^{21}$ The urban status of a Census tract is based on Census Bureau classifications of the 2000 Decennial Census. The Census Bureau defines urban areas using population total and density rules. Urban areas typically include suburbs, but may not include some "exurbs." In the 2010 Census, 81 percent of the U.S. population resided in an urban area, and the displaced worker extract has a mean urban share of 82 percent. We only retain the 62 percent of displaced workers who reside in a 100-percent urban Census tract (urban status can range from 0 to 100 percent, and include suburban areas). The 100-resident worker restriction drops fewer than 1 percent of the displaced workers, as Census tracts have a target population of approximately 4,000 .

${ }^{22}$ We use the urban Consumer Price Index, taking the average for each month in a quarter (because earnings are reported on a quarterly basis).
} 
affiliation is the industry of the establishment from which a worker is displaced. ${ }^{23}$

Table 2 lists the distribution of our sample and some key characteristics across years. The sample share increases from 12.2 percent of displacements in 2005 , to a peak of 17.6 percent in 2008 , and then falls to 10.3 percent in $2011 .{ }^{24}$ This pattern is what we would expect given the timing of the Great Recession, and is also reflected in the distribution of the number of layoff events (column (4)) ${ }^{25}$ Column (7) show that workers displaced in years encompassing the Great Recession (2007Q4-2009Q2) - especially 2009 - had higher pre-separation earnings at their main job. This evidence for earnings from the main job is consistent with mass layoffs falling across a broader swath of workers during the Great Recession.

Using the data on 1.7 billion jobs from the LEHD Infrastructure files spanning the study period, we construct the network measures using employment and hiring information in the quarter after each displacement cohort is separated, and residence information from the same year (approximately 112 million jobs each quarter). This timing is intended to capture the jobs to which workers' networks may connect them in the period following displacement. The network measures described in the previous section are based on individuals aged 19 to 64 who reside in the same Census tract as the displaced worker. For a neighbor to be considered as "employed" in the network measures, the neighbor must have a job with positive earnings in the layoff quarter of a displaced worker as well as in the subsequent quarter. If a neighbor has more than one job spanning both quarters, we only use the job with the highest earnings in the subsequent quarter. All neighbors (employed or not) contribute to the count of neighbors, or $N$. Additionally, the entire sample of workers laid off in the given quarter is excluded from being categorized as "employed," even if that laid off worker had some positive earnings in both periods. These conditions

\footnotetext{
${ }^{23}$ In Appendix Table A1 we provide sample means for these variables for each year separately. Some of the patterns in this table are consistent with what we would expect - for example, the much higher share of mass layoffs in manufacturing and construction around the Great Recession. We verified that our results were qualitatively similar if we reweighted the data to hold the sample composition fixed (relative to 2006Q1) in terms of industry, the factor that varied most across the recession years.

${ }^{24}$ The shortfall in 2006, compared to the surrounding years, is due to an imprecision of Census Bureau geocoding of administrative records for residences in that year. Also note that in 2012, we only use displacements up to and including the third quarter. Data necessary for computing the network measures for those displaced in 2012Q4 was not available at the time of analysis. This explains the lower percentage of observations ( 7.5 percent) in 2012.

${ }^{25}$ The distribution of displacement events has little seasonality, although there are slightly more in third quarters. During the recession, there are some years where displacements are more concentrated in a particular quarter, especially late 2008 and early 2009 .
} 
ensure that if an employer does a lot of hiring in the post-layoff quarter of displaced or unemployed workers who happen to be neighbors, these hires will not be considered as part of the network itself. Although these recent hires may in fact be influenced by networks among displaced workers, we want to avoid the possible influence on our network measures of employers located near the displaced workers simply doing a lot of hiring.

We use this set of employed neighbors and the total count of neighbors to compute a quarterly employment rate for the beginning of the quarter after the layoff. We construct the employment rate similarly to $A E N$, but without the multiplicative factor of the hiring rate.

One limitation of the LEHD Infrastructure files for calculating the network measures is that employers with multiple units in a state do not report the assignment of workers to establishments (this happens in about 44 percent of jobs). ${ }^{26}$ The LEHD program has developed an imputation model to allocate establishments to workers based on establishment size during the worker's tenure at the employer and on the distance between the establishment and the workers place of residence. We use this imputed establishment assignment to identify the establishment a worker was displaced from as well as the location and industry of that establishment, to identify neighbors' establishments and the hiring rates at those establishments for our network measure, and to identify the workplace location of neighbors' employers. ${ }^{27}$ Uncertainty due to lack of definite geography adds noise to the network measures we utilize and may be expected to attenuate our estimates.

We calculate the hiring rate used in the employer-level network measure as the number of new (gross) hires at an employer in a quarter divided by the count of employees at the beginning of that quarter. ${ }^{28}$ On average, employers hired about 13 new workers for each 100 they had at the beginning of the quarter, giving an average hiring ratio of 0.13 with a standard deviation of 0.64 . The hiring rate used in the

\footnotetext{
${ }^{26}$ At a minimum, the state in which an employee works is indicated by the state to which an employer submits unemployment insurance earnings records. In the LEHD Infrastructure files, each employer in a state has a unique State Employer Identification Number. One exception is that multi-unit employers in Minnesota report an establishment assignment along with earnings information for each worker.

${ }^{27}$ The LEHD program actually takes ten independent draws from the "unit to worker" allocation model for the production of public use statistics. For this study, we use just the first of those imputation draws.

${ }^{28}$ We use the Quarterly Workforce Indicators definition of new hires (cannot have worked for an employer in the previous year) and beginning of quarter workers (those with earnings in the previous and current quarter).
} 
tract-level measures is calculated similarly, but at the level of the tract where neighbors work, rather than at their specific employers.

Figure 1 displays various percentiles of the active employer network $(A E N)$ measure and the corresponding control (ATC) across the distribution of displaced workers, by year. For some intuition about the value of $A E N$, consider a job searcher residing in a tract with a median value of the network measure. Based on the median value of 0.108 in 2006, a random neighbor would be expected to have information on approximately one active job vacancy for every ten workers at an employer (with values for the first and third quartiles of 0.09 and 0.13 ). Both exhibit a clear pattern of decline and some recovery associated with the Great Recession, as we would expect from the changes in both the proportion of neighbors employed, and the hiring occurring at their employers (or in the tracts where they work). ${ }^{29}$ By 2009 , the percentiles of $A E N$ had fallen by more than one-third relative to their pre-recession levels.

\section{Empirical Analysis}

With the network measures defined, the analysis is relatively straightforward. To answer the question of whether and where a displaced worker is re-employed following a mass layoff, we conduct a series of regression-based analyses where, for our sample of displaced workers, we regress post-layoff reemployment outcomes in the quarter following layoff on our network measures and a host of variables that control for observable characteristics of the neighborhood, the individual, and their jobs and employers.

Focusing on the first quarter after experiencing a mass layoff between 2005 and 2012, we estimate linear probability models for re-employment of the following form:

$$
\operatorname{Emp}_{i t}=\alpha+X_{i t} \beta+N e t_{i t} \gamma+\varepsilon_{i t} .
$$

The subscript $i$ indexes individuals, $t$ indexes the year/quarter in which the displaced job ended, and $X$ is a series of controls for the individual and his/her neighborhood and employer. Net is a vector that includes $A E N$ - our active employer network measure - and $A T C$.

\footnotetext{
${ }^{29}$ We have top-coded the establishment-based network measure to the $99^{\text {th }}$ percentile of the distribution, because there were some extreme outliers that went up to an order of magnitude higher than the $99^{\text {th }}$ percentile. (This occurred in the establishment measure but not the tract measure, presumably because the latter averages over many workers.) The same applies to the alternative network measures and corresponding controls we discuss later.
} 
Models are estimated for two different employment outcomes. First, Emp is defined as whether the displaced worker is re-employed at all (observed in the LEHD to have positive earnings) in the postdisplacement quarter under consideration. Second, to gauge whether the employment effects of residencebased networks that we estimate actually reflect neighborhood networks, we narrow the re-employment definition so that Emp is an indicator for becoming re-employed at the employer of a neighbor. We look at this latter outcome for the full sample, and for the subsample of only those who become re-employed.

Although the LEHD has limited demographic information as compared to, say, the Current Population Survey, we are still able to control for age, sex, race, and ethnicity, and for earnings and industry affiliation in the year prior to displacement at the primary employer from which the worker is displaced. We also control for annual earnings in the previous year from the displacement job as well as from all other employers. These pre-layoff earnings measures are proxies both for the human capital of displaced workers and for their reservation wage, which can affect their job search behavior. The industry controls may account for unobserved human capital characteristics of workers, as well as for variation in labor demand across industries.

One key factor for which we want to control is local, time-varying labor demand conditions. This is critical because our network measure is influenced by employment rates in each person's tract and by hiring rates at employers and in tracts where neighbors work. For example, we saw that pre-displacement earnings were highest for those laid off at the height of the Great Recession, suggesting that in this period workers who experienced mass layoffs were on average higher quality than workers laid off when economic conditions were stronger, perhaps because mass layoffs during stronger economic conditions are more likely to be related to low productivity of the workforce. To control for this heterogeneity, we include in our regressions layoff fixed effects that are uniquely defined by employer, year, quarter, and county. As a result, we identify the effect of neighborhood labor market networks on post-displacement employment from variation in the network measure within individuals who are laid off in the same quarter, from the same employer, and from establishments in the same county. This variation arises when workers laid off from the same establishment (or set of establishments within a county of a given employer), who therefore 
are likely very similar, live in different neighborhoods. ${ }^{30}$

Thus, these highly-detailed fixed effects account in a non-parametric fashion for labor market conditions that vary spatially, ${ }^{31}$ as well as varying over time as the Great Recession and recovery unfolds, and for differences across workforces experiencing each mass layoff. The workplace-by-year dimension of the fixed effects also controls for the generosity of time-varying state variables such as Unemployment Insurance benefits during and after the Great Recession, which are another component of job searchers' reservation wages, and likely also capture any relevant local policy variation. Hence, we can be more confident that the estimated impacts of the residence-based network measures are not confounded with other policy differences, and, more important, are not confounded with unobservable characteristics of the local labor market or of the displaced worker that are correlated with our network measures.

The only remaining possible confounder to our identification is if workers who worked together prior to being subject to the same mass layoff are sorted across neighborhoods with different network strength based on factors that affect their re-employment probabilities. We have multiple approaches to dealing with the potential for remaining bias in our estimates from this kind of sorting. First, in addition to including in the regressions the layoff-specific fixed effects, we also include the poverty rate in the neighborhood as well as other tract-level controls capturing the demographic and educational composition as well as the residential mobility of the tract; these are time-invariant measures from the 2000 Census. In addition to these static, neighborhood characteristics, we include the quarterly employment rate constructed from the same jobs sample as the network measure. By including the employment rate as a control, we allow only active hiring at one's neighbors to identify the network measure, not social or structural characteristics that might be associated with high attachment to employment. Second, as discussed earlier, we include the tract-level control variable $A T C$, which captures variation across neighborhoods in

\footnotetext{
${ }^{30}$ Ideally one might want to further distinguish layoffs that happen simultaneously across establishments of a given employer within a county if, for example, one establishment houses managerial workers and another houses production workers. However, because of the limits of the LEHD in identifying individual establishments of multiestablishment employers, we do not take this extra step. We thus interpret our employer-by-year-by-quarter-by-county fixed effects as layoff-specific fixed effects. In addition, when we disaggregate our sample into higher- and lowerearning individuals, we may implicitly distinguish between these kinds of establishments even within the same county.

${ }^{31}$ As discussed below, other controls also capture variation in local labor demand conditions.
} 
differential access (via employed neighbors) to Census tracts where hiring is occurring generally. ATC has the advantage - like the employment rate - of being time-varying, and it captures local labor market conditions in the same functional form via which local labor market conditions enter the establishmentlevel network measure $A E N$. Finally, and importantly, if there were still unobserved heterogeneity across workers laid off from the same establishment that is correlated with neighborhood network strength and that affects re-employment per se, it is by definition eliminated in our specifications where the outcome is re-employment at a neighbor's employer, and where we restrict the sample to those who are re-employed at any employer.

We are interested in exploring whether the ability of networks to help displaced workers changed during and after the Great Recession. Hence, we estimate our models for the full sample, as well as separately for each year in the time span 2005-2012. We cluster the standard errors at the same level as the fixed effects to account for common unobservables affecting outcomes of those experiencing the same mass layoff.

\section{Results}

\section{Earnings and employment loss and recovery}

Because the central focus of studies of job displacement to date is the earnings recovery of displaced workers, we first present, in the top panel of Figure 2, the standard depiction in this literature of the observed earnings shock associated with displacement. Although previous analyses have focused on annual earnings over a long horizon, we present the data quarterly both because we only have recent data and (relatedly) because in our empirical analysis we examine a quarterly employment outcome following displacement. The top panel of Figure 2 therefore depicts quarterly earnings (in levels) of the displaced workers, up to one year before and two years after the mass displacement, including workers with zero earnings in post-displacement quarters (all must work in the earlier quarters). Each line tracks the earnings of workers displaced in a given year, with quarter zero giving the average earnings of that cohort in the final quarter with the downsizing employer. Figure 2 shows that there is a drop in average earnings from approximately $\$ 9,000$ in the last quarter prior to displacement to average earnings of between $\$ 3,800$ and 
$\$ 5,300$ in the quarter following displacement, with those earnings rising to a range of about $\$ 5,800$ to $\$ 7,100$ by the $8^{\text {th }}$ quarter, still remaining well below pre-displacement earnings.

Comparing the results by year, those displaced in 2005 and 2006 have the smallest average drop, and within two years they recover on average to within about $\$ 1,900-\$ 2,200$ of pre-displacement earnings. At the other extreme, those displaced in 2009 have the largest drop and remain on average about $\$ 3,500$ (nearly 40 percent) below pre-displacement earnings two years post-displacement. The very sharp earnings losses and slow recovery for those displaced during the Great Recession suggest that if networks are helpful in the re-employment of workers displaced during a recession, the earnings effect could be pronounced.

One obvious question that arises is whether the drop in earnings is driven by those who have no post-displacement earnings, or whether it is driven by a drop in earnings for those who find new employment. The middle panel of Figure 2 uses the same sample of displaced workers but tracks quarterly employment (based on positive earnings). Because all the workers are employed up to and including the quarter of displacement by construction, the share employed for workers displaced in the first quarter of each of the years all overlap at a height of one until the post-displacement quarter. After that, the paths diverge, and then the figure closely parallels the results for earnings, implying that the earnings results are driven primarily by re-employment. In particular, around 64 percent of those displaced in 2005 or 2006 are re-employed in the first post-displacement quarter, but that percentage drops with each subsequent cohort of displaced workers through the 2009 displacements (and then rises beginning in 2010), and the reemployment rate in the quarter after displacement is only 48 percent for those displaced in 2009. In addition, those displaced in 2008 and 2009 have recovered the least by the end of two years after displacement - only 65 percent are employed by then. On the other hand, the recovery of employment appears steepest for those displaced in 2009, suggesting that re-employment of these displaced workers picked up as the recovery began; in contrast the recovery was slower for those displaced earlier but still not employed as the Great Recession began to unfold.

We also confirm, in the bottom panel of Figure 2, that most of the earnings drop observed post- 
displacement (in the top panel) is, in fact, driven by those with zero post-displacement earnings, by producing an analog to the top panel of the figure, dropping observations from any quarter where earnings are zero. As expected, the pattern in this figure shows that post-displacement earnings if one works are not very different from pre-displacement earnings, ${ }^{32}$ so what is most interesting to us - and perhaps more tied to network strength - is re-employment. We therefore focus the rest of our analysis on the re-employment margin.

Other determinations of employment and earnings recovery after displacement

As a preliminary to our core analyses, Table 3 displays the full set of coefficient estimates for our baseline employment regression when estimated by pooling all the years of our sample together. We show results for both the full sample, and a lower-earnings subsample for which we expect local labor market networks to be more important (consistent with the evidence in HMN). Here we do not focus on the estimated effects of the network measures, to which we will turn in depth just below. Rather, we report these to display the estimates of the effects of the demographic, earnings history, and other control variables on employment status in the first quarter after displacement.

Workers who had higher earnings in the previous year, both from the employer from whom they were displaced, and from other employers, had higher re-employment probabilities. Younger workers had much higher re-employment probabilities generally, while older workers, minorities, and women generally had lower post-displacement employment rates, conditional on previous earnings and the other controls. Many of the neighborhood characteristics are positively correlated, so we would not necessarily expect to see the anticipated sign of the effect of each of these characteristics on re-employment of the displaced worker. We do see, however, that re-employment probabilities are higher in neighborhoods with a higher white share, a higher share with some college, and especially a higher employment rate; re-employment probabilities are lower where residential mobility is higher.

\footnotetext{
${ }^{32}$ Our evidence that employment is the key driver of earnings losses is somewhat at odds with what was found in Davis and von Wachter (2011) for displaced workers. This is likely because our data are at a quarterly frequency whereas theirs are annual, implying that an employment shortfall for part of a year will show up as an earnings shortfall in annual data.
} 


\section{The effects of networks on re-employment}

We now turn to our main analyses - the estimated effects of residence-based network measures on employment. The first results, for re-employment per se, are reported in Table 4. The top panel reports estimates for the full sample, the middle panel for those with pre-displacement earnings below $\$ 50,000$, and bottom panel for those with pre-displacement earnings of $\$ 50,000$ or higher. Our conjecture is that local labor market networks are more important for lower-skilled than higher-skilled workers, because these low-skilled workers are more likely to search for jobs in local labor markets. Conversely, we would not be surprised to find much less or no effect of local labor market networks for those with higher earnings. Given that we do not have extensive skill measures in the LEHD data, we use pre-displacement earnings as a proxy for skill.

Column (1) reports pooled results for the full sample period; these are the same coefficient estimates that are reported in column (2) of Table 3. In the top panel, for the full sample, we find a positive and significant estimated coefficient on the active employer network measure $(A E N)$. We think of this estimated coefficient as reflecting the "productivity" of the active employer network in generating new employment for a displaced worker. Note that the estimated effect of the corresponding tract control (ATC) is less than half as large. To interpret the magnitudes, we also provide, below the regression estimates, the implied effects of moving from the $25^{\text {th }}$ to the $75^{\text {th }}$ percentiles of the distributions of these network measures. For $A E N$, the estimates in column (1) indicate that the effect of this interquartile change is to raise the probability of re-employment in the quarter after displacement by 1.15 percentage points (compared to a mean job finding rate of 59 percent, reported in Table 1) $\cdot{ }^{33}$ By way of comparison, a move from the $25^{\text {th }}$ percentile of the tract-level employment rate to the $75^{\text {th }}$ percentile (a change from 60.6 percent to 70 percent) would, based on the estimate of 0.219 in column (1) of Table 3 , entail an increase in postdisplacement employment of 2.06 percentage points. Thus, the overall estimated effect of networks is greater than half the estimated direct effect of the employment rate (which may be in part non-causal); we

\footnotetext{
${ }^{33}$ We multiply the coefficient 0.321 for $A E N$ from Table 4, column (1), by the range from 0.070 to 0.105 , which gives an implied effect of 0.01149 on the indicator for employment.
} 
view this as an economically significant effect. ${ }^{34}$ Meanwhile, a change in $A T C$ from the $25^{\text {th }}$ to $75^{\text {th }}$ percentile would imply an increase in the re-employment probability that is less than one-half as large as the effect of $A E N$ - which could reflect network connections to vacancies in the tracts where neighbors work (net of the effect of vacancies at neighbors' employers), or just local labor market conditions.

In columns (2)-(9) of the top panel of Table 4, we split the sample by year. To interpret these in light of the Great Recession, the recession began in December 2007 and officially ended in June 2009. However, as usual in recessions, the labor market lagged in the Great Recession; payrolls did not start growing consistently until about the second quarter of $2010,{ }^{35}$ and the unemployment rate did not reach its peak until October of $2010 .{ }^{36}$ The results show that the coefficient on $A E N$ was quite stable through 2008 (despite one uptick in 2006). It then fell sharply in 2009 and 2010, corresponding (perhaps with some lag) to the periods when job losses fell the most and payroll employment reached its lowest level. Then in 2011 the estimated coefficient of $A E N$ rebounded to 0.31 before falling again. All of these estimates are statistically significant. The interquartile effects - which also pick up the effects of changes in the distribution of $A E N$ - are reported in the lower panel of the table. They tell a similar story, although with some differences. First, the implied network effects from the interquartile analysis were much lower in both 2009 and 2010 relative to prior years. Second, the estimated decline was sharper - by more than half - than is indicated simply by the change in the estimated coefficient of $A E N$. And third, the network effect did not fully recover in either of the two subsequent years (which are the last two years of our sample). The differences between the changes in the interquartile effects and the coefficient estimates reflects the

\footnotetext{
${ }^{34} \mathrm{We}$ do this comparative calculation for the employment rate because its coefficient was not very sensitive to the inclusion of different sets of controls. In contrast, the estimated coefficients of the tract-level controls like the poverty rate were very sensitive to whether the other highly-correlated tract-level controls (see Table 3 ) were included. We therefore did a similar comparative calculation based on the Census tract poverty rate, omitting all of the other Census-tract characteristics. In this case, a move from the $75^{\text {th }}$ percentile of the poverty rate to the $25^{\text {th }}$ percentile (a change from 18.1 percent in poverty to 5.0 percent in poverty) would entail an increase in post-displacement employment of 1.06 percentage points - a similar magnitude to the effect of the interquartile change in $A E N$. Note that this change in poverty rate, of 13.1 percent, is similar in magnitude to changes induced by the Moving to Opportunity program (Kling et al., 2007), which randomly selected residents of high poverty public housing projects to move into voucher housing. Those in the control group maintained an average neighborhood poverty rate of 0.45 , while those in the experimental and Section 8 groups achieved rates of 0.33 and 0.35 , respectively.

${ }^{35} \mathrm{See}$ http://www.nber.org/cycles/cyclesmain.html (viewed June 5, 2014) and http://data.bls.gov/pdq/SurveyOutputServlet?request_action=wh\&graph_name=CE_cesbref1 (viewed April 15, 2015). ${ }^{36} \mathrm{See} \mathrm{http://data.bls.gov/timeseries/LNS14000000} \mathrm{(viewed} \mathrm{March} \mathrm{26,} \mathrm{2015).}$
} 
changes in $A E N$ depicted in Figure 1, which fell during and immediately after the Great Recession as hiring ground almost to a halt, with the distribution (and interquartile range) of $A E N$ narrowing. ${ }^{37}$

To interpret the magnitudes, consider a hypothetical worker laid off in the pre-recession period. Conditional on other regression controls, we estimate that if the worker's active employer network $(A E N)$ were at the median of the distribution instead of zero, this would boost their re-employment probability by 3.4 percentage points or a 5.3 percent increase $(\{0.313 \cdot 0.108\} / 0.633$, using the column (2) 2005 regression estimate, the 2005 median for $A E N$, and the mean re-employment rate for 2005 displacements in Table 2), relative to having no network linking him or her to job vacancies. In contrast, the same worker, laid off in 2010 with $A E N$ at the median of the distribution in that year, would only have a boost in re-employment probability of 1.3 percentage points, or 2.4 percent higher than if he or she had no such network. This strikes us as an economically significant reduction in the effectiveness of the residence-based labor market networks in 2010 relative to 2005 .

In the middle panel, for the low-earnings subsample (a large share of the full sample), the qualitative results are quite similar. The coefficient estimates on $A E N$ are a shade larger in magnitude, and the interquartile effects prior to the Great Recession are larger. The decline in the effect of networks during the Great Recession is also similar. In contrast, for the high-earnings subsample, reported in the bottom panel, we find no evidence of an effect of local labor market networks on re-employment of displaced workers. Going forward, therefore, we focus only on the full-sample and low-earnings sample results.

To this point, these estimates suggest that labor market networks that link workers to their neighbors' employers are effective at helping displaced workers - especially lower-skilled ones - become re-employed. That said, networks appear to have been quite a bit less effective in aiding the transition back to work for displaced workers during the depths of the labor market disruptions of the Great Recession (2009-2010), as compared to the period after or especially to the period before. In terms of changes in the data, this happened for two reasons. First, the distribution of the employer network measure $A E N$ shifted

\footnotetext{
${ }^{37} \mathrm{We}$ also estimated all specifications with linear and quadratic terms in the network measures. There was frequently evidence of diminishing effects of the network measures at higher values, but the implied partial derivatives of the outcomes with respect to the network measures were virtually always positive throughout the distributions of the network measures.
} 
down and narrowed during the Great Recession, so that network connections to vacancies themselves diminished - more so in the more networked neighborhoods. Second, the fact that the estimated coefficient on $A E N$ fell during the recession suggests that, conditional on the network measures, the productivity of these networks in helping displaced workers find work also fell during the recession. ${ }^{38}$

To provide additional information on the sources of changes in the effects and importance of network strength over the course of the Great Recession, Figure 3 plots two graphs - one for the full sample and one for the low-earnings sample. In each, the black solid line plots the interquartile effects of $A E N$ in each year; these estimates directly match those in the top and middle panels of Table 4 . We see a clear decline as we move into the Great Recession, and some evidence of a recovery in 2011 and 2012. We then separately use the estimated coefficients on $A E N$, and the estimated changes in its distribution, to gauge how much of the change in the overall effect is attributable to changes in the productivity of networks as measured by the estimated regression coefficients as opposed to changes in the distribution. The dotted line in each panel holds the interquartile range constant at its 2005 level, and plots the product of this with the estimated coefficient in each year, hence capturing only the change in the estimated effect of $A E N$. In contrast, the dashed line holds the estimated productivity of the network constant at its 2005 value, and uses the observed changes in the interquartile range of $A E N$. As the graph shows, both types of changes generate declines in the estimated impact of network strength, but the change in the distribution of $A E N$ accounts for more of the overall change.

\section{The effects of networks on re-employment at a neighbor's employer}

In Table 5 we focus on whether the re-employment occurred at an employer of a worker in the neighborhood network, so the outcome is hiring at an employer of a neighbor, versus re-employment at some other employer or no re-employment. This analysis provides more direct evidence on whether our

\footnotetext{
${ }^{38}$ To the extent that this is true, one possible explanation for this finding is that neighbors may have alerted job searchers to fewer vacancies, either because they had less actual knowledge of whether there were vacancies during the recession (perhaps because employers did not have to do as much to encourage recruitment of applicants). Another possible explanation for the fall in the productivity of networks as a result of the Great Recession - and the broad measure in particular - may be related to the evidence in Davis et al. (2012), who show that employers filled vacancies at a slower rate during and after the Great Recession, potentially because the transactions costs of hiring and firing weighed more heavily on hiring decisions in the face of unusually high uncertainty about product demand.
} 
network measures are in fact picking up either referrals of neighbors to employers or the transmission to neighbors of information about job vacancies. The evidence provides striking confirmation of the network interpretation of the previous evidence. The top panel reports estimates for the full sample, and the bottom panel for the low-earnings sample. Every coefficient estimate in Table 5 - for both the pooled years and individual years - is larger than the corresponding estimate in Table 4. And note that here, unlike in Table 4, the estimated coefficient is higher in 2012 as in 2011, and both are higher than the estimates in 2009 and 2010. There is also evidence, for both the full sample and the low-income sample, of smaller interquartile effects of networks on re-employment at a neighbor's employer in 2009 and 2010, the worst years of the labor market's downturn resulting from the Great Recession. Finally, the overall estimated effects of network strength-as reflected most directly in the interquartile effects - are again larger for the lowearnings sample.

In Table 6 we take this one step further. We continue to consider re-employment at a neighbor's employer as the outcome of interest, but we also condition on re-employment by excluding from the sample those who were not re-employed in the quarter following displacement. That is, we examine the impact of networks on channeling displaced workers into re-employment at a neighbors' workplace rather than reemployment elsewhere. The evidence of network effects is qualitatively similar to that of Table 5 , but the estimated coefficients and the interquartile effects are even larger.

Figure 4 presents similar information to earlier on the role of changes in the estimated productivity of the network measures versus changes in the distributions of the network measures themselves, in this case for the regression estimates in Table 5, and Figure 5 does the same for the regression estimates in Table 6 (which condition on re-employment). Again, in both cases the decline in the effect of networks during the Great Recession is driven more by changes in the network measures than by changes in the estimated coefficients, although there is still some evidence - especially in Figure 4 - of a reduction in the estimated effect of networks (holding the distribution of network measures fixed) during the Great Recession.

In our view, because the sample used in Table 6 consists only of those re-employed in the quarter 
after displacement, it provides the clearest evidence that the mechanism by which neighborhood labor market networks affect the re-employment of displaced workers is by leading to new jobs where neighbors are employed. That said, taken together, the results in Table 6 that indicate that networks channel displaced workers into re-employment specifically at neighbors' employers, coupled with the evidence in Table 4 that re-employment itself is increased via network strength, provide strong evidence that networks - particularly for lower-skilled workers - are a mechanism by which the economic losses of displaced workers can be at least partly ameliorated.

\section{$\underline{\text { Robustness to controls }}$}

We have already discussed how our extensive controls, including the highly-detailed employer/year/quarter/county fixed effects, go a long way toward mitigating the possibility that our estimated effects of networks instead reflect sorting of workers based on unobserved factors that affect both re-employment probabilities and the network measures. Moreover, for the final specifications discussed above, where the outcome is re-employment at a neighbor's employer conditional on becoming reemployed anywhere, such a selection or sorting story seems even less plausible.

Nonetheless, one additional way to gauge whether there is remaining upward bias in our estimates from unobserved heterogeneity is to ask whether the estimated coefficients on our network measures tend to be larger when some of the controls are omitted. Such an analysis is not decisive, of course, because it only speaks to the variation captured in the observable variables we have. But if additional controls tend not to reduce the estimated network coefficients, it is hard to imagine other (less obvious) unobservables that, if observable and included in the regression, would themselves reduce the estimates. ${ }^{39}$

To that end, Table 7 reports estimates with different sets of controls. Here we only report estimates pooling across all years (and continue to report estimates for the full sample and the low-earnings sample). Moreover, we do this for what we regard as our best evidence of network effects - the estimates paralleling Table 6 for re-employment at a neighbor's employer conditional on re-employment. Columns (1) and (2) of the table repeat the estimates from Table 6. Columns (3) and (4) include the detailed fixed effects while

\footnotetext{
${ }^{39}$ Altonji et al. (2005) formalize this argument.
} 
omitting the other controls, and columns (5) and (6) and then (7) and (8) add alternately (but not simultaneously) the worker or neighborhood controls. What we see in these different specifications is very little evidence that the estimated coefficients are larger when controls are omitted. Indeed, in columns (3) and (4) and columns (7) and (8), the estimates are very robust, while in columns (5) and (6) they are lower, rather than higher. We take these results as evidence that our estimates do not reflect positive bias from sorting across neighborhoods in a manner that could generate spurious evidence of network effects. ${ }^{40}$

\section{Alternative Theoretical Perspectives on Labor Market Networks}

Having established our key results for our active employer network measure, in this penultimate section we consider in greater depth the conceptualization of local labor market networks. In particular, we extend our analysis of job displacement and re-employment to try to garner evidence on the separate roles of the two main mechanisms by which networks matter for re-employment, as analyzed in previous theoretical frameworks. The first of these is the model in which employed workers in a network transmit information about vacancies to job searchers; the second is the model in which network contacts provide information about potential hires to their employers.

It is hard to distinguish empirically between these two channels of network connections, partly because - as in our work - explicit referrals are generally unobserved. A few recent studies are exceptions, although most use data that are small in scale and unique in context. Brown et al. (2014) use observational data from a company-level dataset with explicit information on which job candidates were referred by an employee, and find important referral effects on early wages and on job tenure, especially for workers at lower skill levels (in particular, support staff). Pallais and Sands (forthcoming) and Beaman and Magruder (2012) use field experiments (in an online marketplace and in a rural setting in India, respectively) and find that referrals by initial recruits into the study are more productive than other hires. In contrast, Burks et al. (2015) use a large observational dataset on referrals from nine large firms spanning three industries and

\footnotetext{
${ }^{40} \mathrm{We}$ also estimated the specifications with these alternative sets of controls using the dependent variables from Tables 4 and 5 - just re-employment, and re-employment at a neighbor's employer (without conditioning on reemployment). The qualitative result is the same; in no case were the estimated effects larger when controls were omitted. (And indeed when both the worker and neighborhood controls were omitted the estimated coefficient for simple re-employment was negative - very different from what would be predicted if these controls pick up important dimensions of sorting.)
} 
find little effect on productivity or wages, but positive referral effects on profits via lower turnover and recruiting costs. In all of these contexts, the evidence is most consistent with networks reducing information imperfections on the employer side, but this is often the only channel of network effects that these studies are designed to detect.

More indirect evidence comes from our recent work (HKN), in which, paralleling Brown et al. and Burks et al. (although without explicit information on referrals), we use observational data to test theoretical predictions about the effects of residence-based labor market networks that act by providing employers with information about the quality of job applicants. ${ }^{41}$ If networks facilitate good job matches, wages should be higher and turnover should be lower (particularly at low levels of tenure) for workers who are better networked at the time they are hired. We find robust evidence that workers who are more residentially networked to their co-workers at the time of hire have lower rates of turnover. ${ }^{42}$ When we use wages as an outcome, we find evidence for blacks, Hispanics, and Asians that wages are higher when workers are more networked to neighbors, although the result is less clear for whites. ${ }^{43}$

\section{Alternative network measures}

In the analysis presented in this section of the paper we introduce two measures of network strength that try to capture key elements of the two models of networks. The first measure emphasizes the role of networks in providing information about job vacancies to job searchers (Calvó-Armengol and Jackson, 2007; Ioannides and Soetevent, 2006). We refer to this as the "active broad employer network" $(A B E N)$ measure, where the "breadth" we measure is intended to capture the number and diversity of possible network contacts a displaced worker can access using his or her neighbors to learn about vacancies.

The second measure emphasizes the role of networks in providing information about workers to

\footnotetext{
${ }^{41}$ See related work in Simon and Warner (1992) and Dustmann et al. (forthcoming).

${ }^{42}$ Reflecting the difficulty of distinguishing between the different models or hypotheses regarding networks, it is possible that better matches result simply from potential workers having information about more job matches, enabling them to choose a better one.

${ }^{43}$ Schmutte (2015) finds a different kind of evidence of a matching role of networks - finding that workers are more likely to move to a higher-paying job when their neighbors are employed in high-paying firms, and that these local networks match high-ability workers to high-paying firms.
} 
firms (Montgomery, 1991). We refer to this as the "active deep employer network" (ADEN) network measure, where the "depth" we measure is intended to capture the idea that networks serve to provide information to potential employers (and job seekers) about the potential productivity of a job match between a potential employer and a job seeker, and so the more signals an employer gets about the productivity of a job seeker, the more likely a job match is to be made.

The rationale for the broad measure, $A B E N$, is that if a job searcher's network is productive because employed neighbors provide him/her with information on vacancies, we might expect that the network is more productive the more employers (with vacancies) the job searcher is connected to through the network, which $A B E N$ captures. ${ }^{44}$ One way to think about this is that when two (or more) neighbors who are employed in the same establishment give one job searcher information on a vacancy in the establishment, they are transmitting redundant information (as in Ioannides and Soetevent, 2006), whereas two (or more) neighbors who are employed in separate establishments have unique vacancy information to transmit. Thus, $A B E N$ drops the potential double-counting that, as noted earlier, is included in $A E N$.

The rationale for the deep measure, $A D E N$, is that if a job searcher's employed neighbors give their employers information about the job searcher's quality (or the quality of a potential match between the job searcher and the firm), then having multiple neighbors work for the same employer is more productive for the job searcher than having neighbors work for separate employers. In particular, multiple neighbors who provide a signal to the same employer about the job searcher's (match) quality serve to increase the signal of the quality of a potential match between the job searcher and their shared employer than the signals provided by multiple workers each to unique employers. ${ }^{45}$

The formula for $A B E N$ is similar to that for $A E N$, with the difference being that it is just the average of the hiring rates for all the job searcher's neighbors' employers, giving an equal weight to each employer:

\footnotetext{
${ }^{44}$ The breadth of the network may also matter because it is likely to be related to greater diversity in job vacancies (for example, by industry), and hence a broader network may be more likely to lead to a good match. ${ }^{45}$ Or, having multiple neighbors at the same employer may make a referral more likely.
} 


$$
A B E N=\frac{1}{N} \sum_{e}^{E} \frac{H_{e}}{L_{e}}
$$

where, using the same notation as before, $N$ is the number of neighbors in the job searcher's Census tract at the time of his/her displacement, $E$ is the number of unique employers for whom neighbors work, and $\frac{H_{e}}{L_{e}}$ is the ratio of new hires at the employer $e$ in the quarter following the job searcher's displacement, divided by the count of employees at that employer in the beginning of the post-displacement quarter. The key difference relative to $A E N$ is that neighbors who work in the same establishment only contribute once to the measure. We take the average across all of the job searcher's neighbors, $N$, rather than just across employers (or just across employed neighbors), to reflect the fact that the more of the job searcher's neighbors who are not employed, the less likely it is that any given neighbor he/she speaks with will have new job information.

Paralleling the tract-level counterpart to $A E N(A T C)$, we construct a tract-level counterpart to $A B E N$, which we denote $A B T C$ ("active broad tract control"), to capture two possibilities. The first is the possibility of additional network connections; the job searcher's employed neighbors may have information about vacancies in their Census tract generally that can be transmitted. However, ABTC may also simply capture local labor market strength as well. It is constructed as:

$$
A B T C=\frac{1}{N} \sum_{w}^{W} \frac{H_{w}}{L_{w}}
$$

where the hiring rates are summed across unique workplace Census tracts (indexed by $w$ ) in which any of the job searcher's $N$ neighbors are employed.

For our measure of labor market depth, we add the network isolation index - denoted $N I$ - from HNM to our measure $A E N$. NI is intended to capture the extent to which employees of a business establishment come disproportionately from people who live in the same neighborhood (defined as a 
Census tract) and is calculated as the share of a neighbor's co-workers who are also co-residents. ${ }^{46} \mathrm{We}$ define a job searcher's active deep employer network $(A D E N)$ measure as a weighted average of the observed network indexes for his/her neighbors:

$$
A D E N=\frac{1}{N} \sum_{i}^{N} N I_{i} \frac{H_{i e}}{L_{i e}} \cdot I_{i} .
$$

Here, we again sum across all of a job searcher's neighbors, rather than across employers. For individuals living in the same Census tract who are not employed (including those who have been recently displaced), $N I_{i}$ is, by definition, equal to zero since they have no network contacts at their place of employment. ${ }^{47}$ If the individual has many neighbors who are not employed, or who are employed but in establishments where no other neighbors are employed, $A D E N$ will be low. Conversely, if the individual has many neighbors who are employed in workplaces that are doing a lot of hiring, and whose co-workers consist largely of other neighbors, $A D E N$ will be high.

Finally, we build a parallel measure of the depth of the network at the level of the workplace Census tract, which we term the "active deep tract control" measure, as follows:

$$
A D T C=\frac{1}{N} \sum_{i}^{N} T I_{i w} \frac{H_{i w}}{L_{i w}} \cdot I_{i}
$$

For each worker, TI gives the share of total workers in a workplace Census tract who reside in the same tract as that worker - i.e., having the same origin and destination tracts in their commute. It is

\footnotetext{
${ }^{46}$ To construct the network measure, HNM first identify all establishments within each Census tract, and the workers in these establishments. They then compute for each worker in the sample the percentage of his or her co-workers who come from the same residential neighborhood (Census tract). For worker $i$ this observed network index is:

$$
N I_{i}=\left[\sum_{j \neq i} I^{R}(i, j) \cdot I^{E}(i, j)\right] /\left[\sum_{j \neq i} I^{E}(i, j)\right],
$$

where $I^{R}(i, j)$ is an indicator for whether co-worker $j$ of worker $i$ also lives in the same residential neighborhood as $i$, and $I^{E}(i, j)$ is an indicator for whether $i$ and $j$ work in the same establishment. The sums in the numerator and denominator are taken over all workers (other than the worker $i$ ) who work in worker $i$ 's establishment. Their ratio is the share of co-workers with whom each worker is co-resident. In HNM, the observed network index for an individual, $N I_{i}$, is averaged over all workers in the establishment, to characterize the level of residential network connectedness that characterizes each employer.

${ }^{47} \mathrm{We}$ also define workers at single-employee firms (who have no co-workers) as having an $N I_{i}$ of zero.
} 
constructed in an identical manner as $N I$ (which is why we use a similar notation), except that we use the workplace Census tract rather than the establishment. Neighbors with no employment effectively contribute zero to the deep tract measure, as do neighbors working in Census tracts that are doing no gross hiring. In HKN we termed this measure the "Transportation Isolation index" because of the possibility that residential neighbors may work in the same Census tract because shared transportation opportunities lead to shared access to jobs in that Census tract, rather than a mechanism by which shared information via networks leads to shared access to jobs in that Census tract. ${ }^{48}$ Under this interpretation, paralleling the discussion of $A B T C$ above, $A D T C$ serves as a control variable for estimating the effect of $A D E N$; it could also reflect network contacts that connect a worker to other employers in the tracts where their neighbors work, although this interpretation seems less tenable with regard to the deep network measure intended to capture the network mechanism whereby workers refer neighbors to their employers.

\section{Results}

The estimated effects of $A B E N$ and $A D E N$ are reported in Table 8 - as in Table 7 for the pooled years, but for both the full sample and the low-earnings sample. We also report results corresponding to each of the analyses in Tables 4-6 - for re-employment, for re-employment at a neighbor's employer, and for the latter but conditional on re-employment. ${ }^{49}$ The evidence is quite clear. We find positive and significant coefficient estimates of both of these more-refined network measures, regardless of the specification of the dependent variable or the sample. Although the estimated coefficients for the deep measure $(A D E N)$ are larger, the level and range of $A D E N$ is much smaller. ${ }^{50}$ As a result, the interquartile effects of the broad measure are much greater, by a ratio of nine or more.

Finally, although not reported in the table, when we estimated these specifications with the two network measures year-by-year, there was - like for $A E N$ - evidence that the effect of the broad network

\footnotetext{
${ }^{48}$ As explained in HKN, the inclusion of $A D T C$ along with $A D E N$ parallels the adjustment of $N I$ in $H N M$ for the clustering that can occur randomly.

${ }^{49}$ Note that we do not report the estimated coefficients of $A B T C$ and $A D T C$ in the table. The estimated coefficients of $A B T C$ were negative, and the estimated coefficients of $A D T C$ were positive. But given that these variables could reflect network effects as well as serve as controls (with many other controls included), and given that both are included together, we do not seek to interpret these estimates.

${ }^{50}$ In 2006, the $25^{\text {th }}$ and $75^{\text {th }}$ percentiles of $A B E N$ are 0.069 and 0.097 ; the corresponding percentiles of $A D E N$ are 0.00079 and 0.00256 .
} 
measure $(A B E N)$ declined during the Great Recession and then recovered. But the evidence was less clear for the deep measure. And like for $A E N$, this change over time in the effect of $A B E N$ was attributable in part to changes in its estimated effect or productivity, but more so to the distribution of $A B E N$ shifting down and narrowing during the Great Recession, so that network connections to vacancies themselves declined.

Overall, these estimates suggest that labor market networks that link workers to their neighbors' employers are effective at helping displaced workers become re-employed, especially the broad network measure $A B E N$ that captures the scope of vacancies at neighbors' establishments. That said, networks that provide information about job vacancies to job searchers (captured in $A B E N$ ) were clearly less effective in aiding the transition back to work for displaced workers during the depths of the labor market disruptions of the Great Recession (2009-2010), as compared to the period either before or after.

\section{Conclusion}

In this paper we develop measures of what we refer to as active residence-based labor market networks, the strength of which vary over time and across residential neighborhoods. By studying workers who lost jobs in mass layoffs, using the detailed spatial data on place of work and place of residence in the LEHD data, and considering different refinements of the measurement of re-employment, we are able to address multiple potential threats to the identification of network effects on finding jobs. We also test for the effects of these measures of network strength against the backdrop of the Great Recession, estimating their impact on the re-employment of displaced workers prior to, during, and after the Great Recession. In so doing, we provide the first evidence, to our knowledge, of changes in the role of labor market networks over the course of entry into and recovery from the Great Recession.

Our main measure of local labor market networks, $A E N$ (for "active employer network"), captures gross hiring at the employed neighbors of a displaced worker, and hence can capture the effects of networks either via information passed along to job searchers about job vacancies or via referrals to employers about job searchers. We find positive effects of this network measure on re-employment of displaced workers generally, and more so when we focus on low earners for whom local labor market 
networks should be more important. We also find strong effects of this network measure on re-employment specifically at a neighbor's employer, providing more direct evidence of network effects. Finally, our strongest evidence is the positive effect of this network measure on re-employment at a neighbor's employer, even conditional on re-employment. In our view, the estimated effect of networks is economically significant; as an illustrative example, we showed that the effect of a change from the $25^{\text {th }}$ to the $75^{\text {th }}$ percentile of the tract-level distribution of our main network measure is to increase the probability of re-employment in the quarter after displacement by 1.15 percentage points (1.95 percent), a bit more than half the effect of the local employment rate increasing from the $25^{\text {th }}$ to the $75^{\text {th }}$ percentile.

When we examine the evidence year-by-year through our sample, we find that the effect of networks in facilitating re-employment fell - sometimes substantially - during the weak labor market of the Great Recession and its immediate aftermath. This result is driven by multiple forces - neighbors lost their jobs in larger numbers, employers slowed their hiring substantially or stopped hiring altogether, and to some extent, networks became less productive.

We also consider measures of network strength intended to differentiate between the two main theoretical types of network models. We define a "deep" active network measure $(A D E N)$ that is intended to capture referrals of job searchers to hiring employers, and a "broad" measure $(A B E N)$ that is intended to capture the provision of information about jobs to job searchers. We find evidence that both measures of networks have positive effects on re-employment - again more so for low earners. And we again find strong effects of both measures on re-employment at a neighbor's employer - unconditional and conditional on re-employment. The estimated effects of the broad measure are substantially stronger. Moreover, the broad measure exhibits a similar pattern to our catch-all $A E N$ measure of a weaker effect during the Great Recession, suggesting that it was the effects of networks via information about vacancies that declined during the Great Recession.

The predominant source of decline in the overall effects of networks during the Great Recession arises from changes in the distribution of the network measures - owing to fewer employed neighbors and less gross hiring at neighbors' employers. In addition, we find some evidence that the productivity of 
networks declined during the recession. While it is distressing that the overall effects of networks declined during the Great Recession, it is important to emphasize that throughout the entire period of our study, strong residential labor market networks helped displaced workers get back to work more quickly. 


\section{References}

Abowd, John M., Bryce Stephens, Lars Vilhuber, Fredrik Andersson, Kevin McKinney, Marc Roemer, and Simon Woodcock. 2009. "The LEHD Infrastructure Files and the Creation of the Quarterly Workforce Indicators.” In Timothy Dunne, J. Bradford Jensen, and Mark J. Roberts (Eds.), Producer Dynamics: New Evidence from Micro Data. Chicago, IL: University of Chicago Press for the National Bureau of Economic Research, 149-230.

Altonji, Joseph G., Todd E. Elder, and Christopher R. Taber. 2005. "Selection on Observed and Unobserved Variables: Assessing the Effectiveness of Catholic Schools." Journal of Political Economy, 113(1), February, 151-184.

Bandiera, Oriana, Iwan Barankay, and Imran Rasul. 2005. "Social Preferences and the Response to Incentives.” Quarterly Journal of Economics, 120(3), August, 917-962.

Bayer, Patrick, Stephen Ross, and Giorgio Topa. 2008. "Place of Work and Place of Residence: Informal Hiring Networks and Labor Market Outcomes." Journal of Political Economy, 116(6), December, 1150-1196.

Beaman, Lori, and Jeremy Magruder. 2012. "Who Gets the Job Referral? Evidence from a Social Networks Experiment.” American Economic Review, 102(7), December, 3574-3593.

Brown, Meta, Elizabeth Setren, and Giorgio Topa. 2014. "Do Informal Referrals Lead to Better Matches? Evidence from a Firm's Employee Referral System.” IZA Discussion Paper No. 8175.

Burks, Stephen V., Bo Cowgill, Mitchell Hoffman, and Michael Housman. 2015. "The Value of Hiring through Employee Referrals." Quarterly Journal of Economics, 130(2), May, 806-839.

Calvó-Armengol, Antoni, and Matthew O. Jackson. 2007. "Networks in Labor Markets: Wage and Employment Dynamics and Inequality." Journal of Economic Theory, 132(1), January, 27-46.

Cingano, Federico, and Alfonso Rosolia. 2012. "People I Know: Job Search and Social Networks." Journal of Labor Economics, 30(2), April, 291-332.

Davis, Steven J., Jason Faberman, and John C. Haltiwanger. 2012. "Recruiting Intensity during and after the Great Recession: National and Industry Evidence." American Economic Review Papers \& Proceedings, 102(3), May, 584-588.

Davis, Steven J., and Till M. von Wachter. 2011. "Recessions and the Cost of Job Loss." Brookings Papers on Economic Activity, Fall, 1-55.

Dustmann, Christian, Albrecht Glitz, and Uta Schönberg. "Referral-Based Job Search Networks." Forthcoming in Review of Economic Studies.

Glitz, Albrecht. 2014. "Coworker Networks in the Labour Market.” Unpublished paper.

Granovetter, Mark S. 1974. Getting a Job: A Study of Contacts and Careers. Cambridge, MA: Harvard University Press.

Ham, John C., and Samuel A. Rea Jr. 1987. "Unemployment insurance and male unemployment duration in Canada." Journal of Labor Economics, 5(3), July, 325-353.

Hellerstein, Judith K., Mark Kutzbach, and David Neumark. 2014. "Do Labor Market Networks Have an Important Spatial Dimension?” Journal of Urban Economics, 79(3), January, 39-58.

Hellerstein, Judith K., Melissa McInerney, and David Neumark. 2011. "Neighbors and Co-Workers: The Importance of Residential Labor Market Networks." Journal of Labor Economics, 29(4), October, 659-695.

Hellerstein, Judith K., and David Neumark. 2012. "Employment Problems in Black Urban Labor Markets: Problems and Solutions." In Philip N. Jefferson (Ed.), The Oxford Handbook of the Economics of Poverty. Oxford, UK: Oxford University Press, 164-202. 
Hellerstein, Judith K., David Neumark, and Melissa McInerney. 2008. "Spatial Mismatch vs. Racial Mismatch?” Journal of Urban Economics, 64(2), September, 467-479.

Ioannides, Yannis M., and Linda Datcher Loury. 2004. "Job Information, Networks, Neighborhood Effects, and Inequality.” Journal of Economic Literature, 42(4), December, 1056-1093.

Ioannides, Yannis M., and Adriaan R. Soetevent. 2006. "Wages and Employment in a Random Social Network with Arbitrary Degree Distribution." American Economic Review, 96(2), May, 270-274.

Jackson, Matthew O. 2008. Social and Economic Networks. Princeton, NJ: Princeton University Press.

Jacobsen, Louis S., Robert J. LaLonde, and Daniel G. Sullivan. 1993. "Earnings Losses of Displaced Workers." American Economic Review, 83(4), September, 685-709.

Kain, John. 1968. "Housing Segregation, Negro Employment, and Metropolitan Decentralization." Quarterly Journal of Economics, 82(2), May, 175-197.

Kling, Jeffrey R., Jeffrey B. Liebman, and Lawrence F. Katz. 2007. "Experimental Analysis of Neighborhood Effects.” Econometrica, 75(1), January, 83-119.

Kroft, Kory, Fabian Lange, and Matthew Notowidigdo. 2013. "Duration Dependence and Labor Market Conditions: Evidence from a Field Experiment." Quarterly Journal of Economics, 128(3), August, 1123-1167.

Montgomery, James D. 1991. "Social Networks and Labor-Market Outcomes: Toward an Economic Analysis." American Economic Review, 81(5), December, 1408-1418.

Neumark, David, and Helen Simpson. 2015. "Place-Based Policies." In Gilles Duranton, Vernon Henderson, and William Strange (Eds.), Handbook of Regional and Urban Economics, Vol. 5. Amsterdam, Netherlands: Elsevier, 1197-1287.

Pallais, Amanda, and Emily G. Sands. "Why the Referential Treatment? Evidence from Field Experiments on Referrals." Forthcoming in Journal of Political Economy.

Saygin, Perihan Ozge, Andrea Weber, and Michèle A. Weynandt. 2014. "Coworkers, Networks, and Job Search Outcomes." Unpublished paper.

Schmutte, Ian M. 2015. "Job Referral Networks and the Determination of Earnings in Local Labor Markets." Journal of Labor Economics, 33(1), January, 1-32.

Simon, Curtis J., and John T. Warner. 1992. "Matchmaker, Matchmaker: The Effect of Old Boy Networks on Job Match Quality, Earnings, and Tenure.” Journal of Labor Economics, 10(3), July, 306-330.

Sullivan, Daniel, and Till von Wachter. 2009. "Job Displacement and Mortality: An Analysis Using Administrative Data." Quarterly Journal of Economics, 124(3), August, 1265-1306. 
Figure 1: Percentiles of distributions of active employer network measure and corresponding tract control, by year
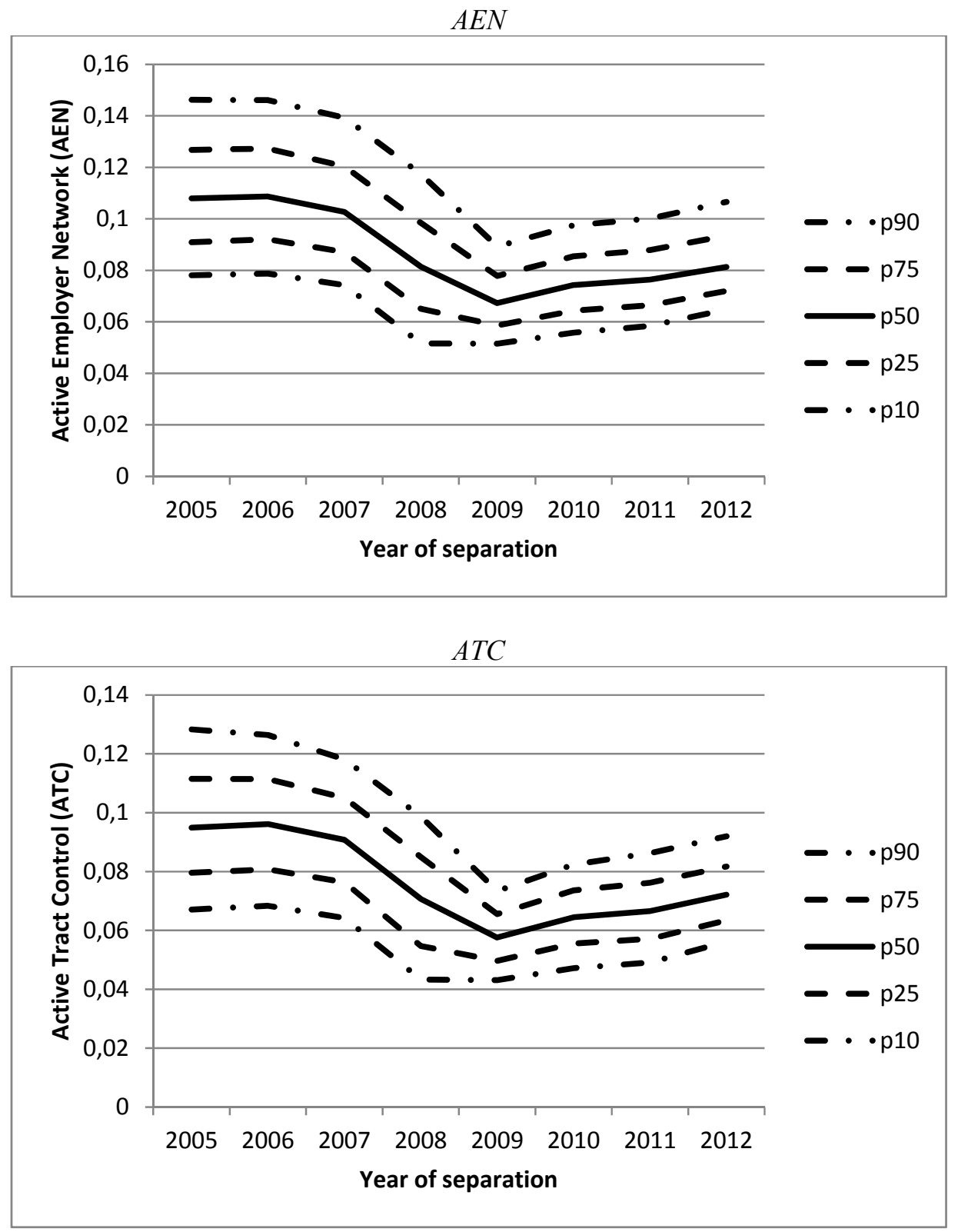

Notes: Calculations from LEHD data. 
Figure 2: Earnings and employment of displaced workers, by year of displacement

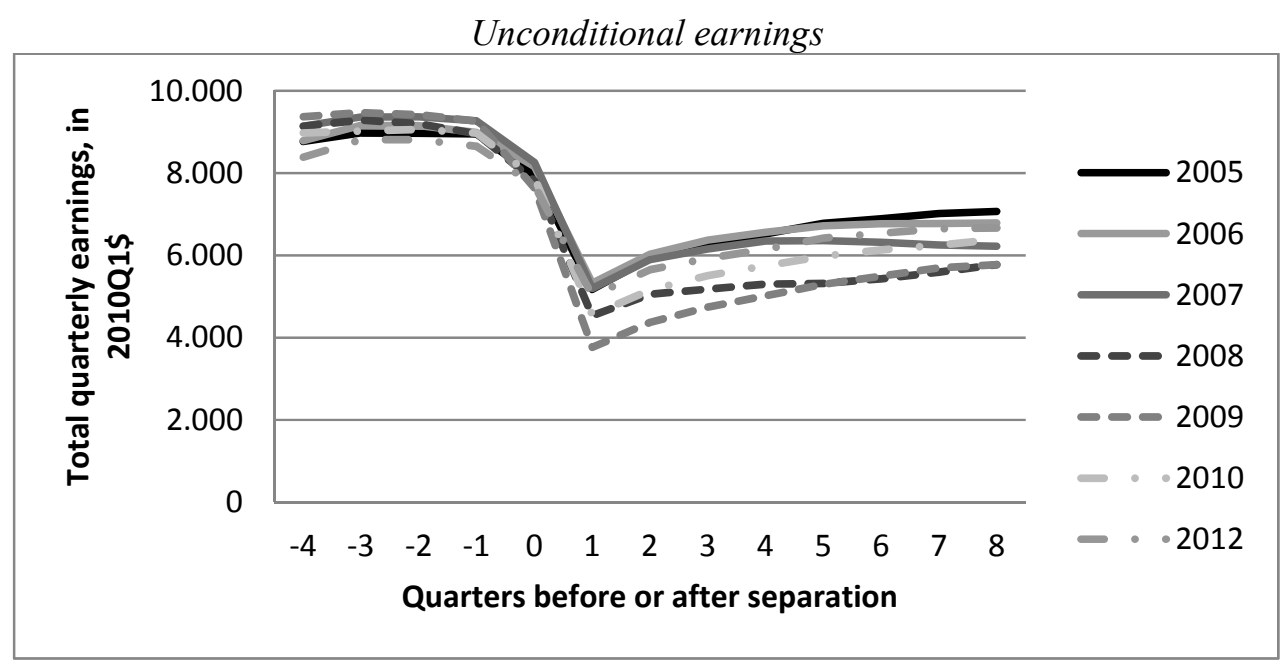

Employment rate

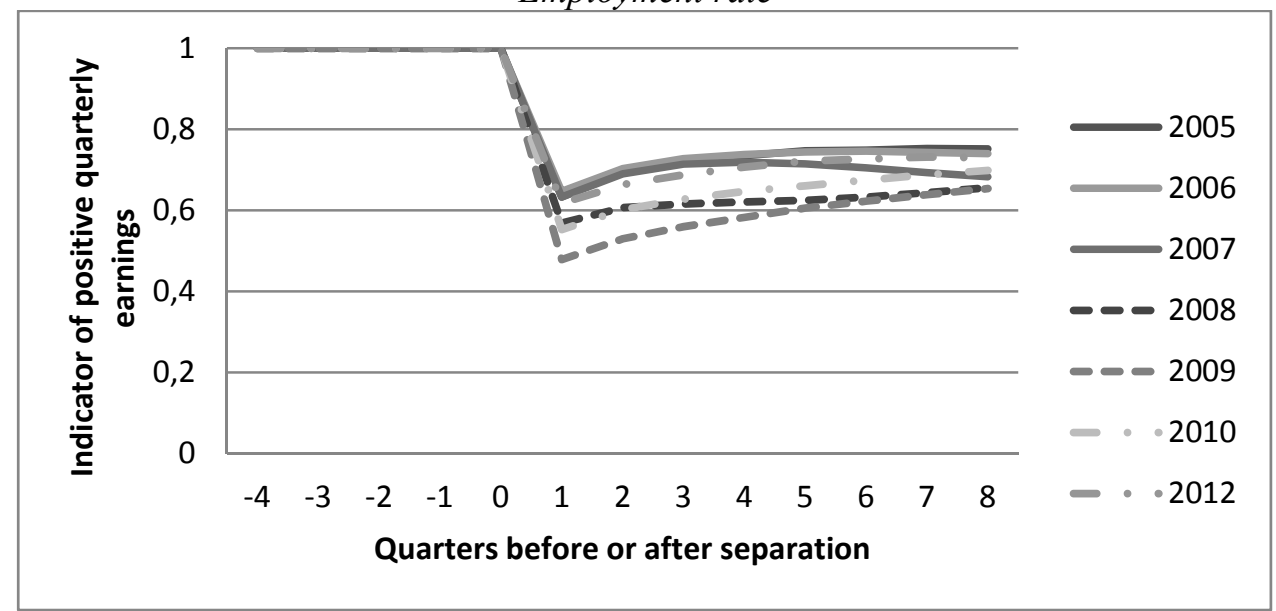

Conditional earnings

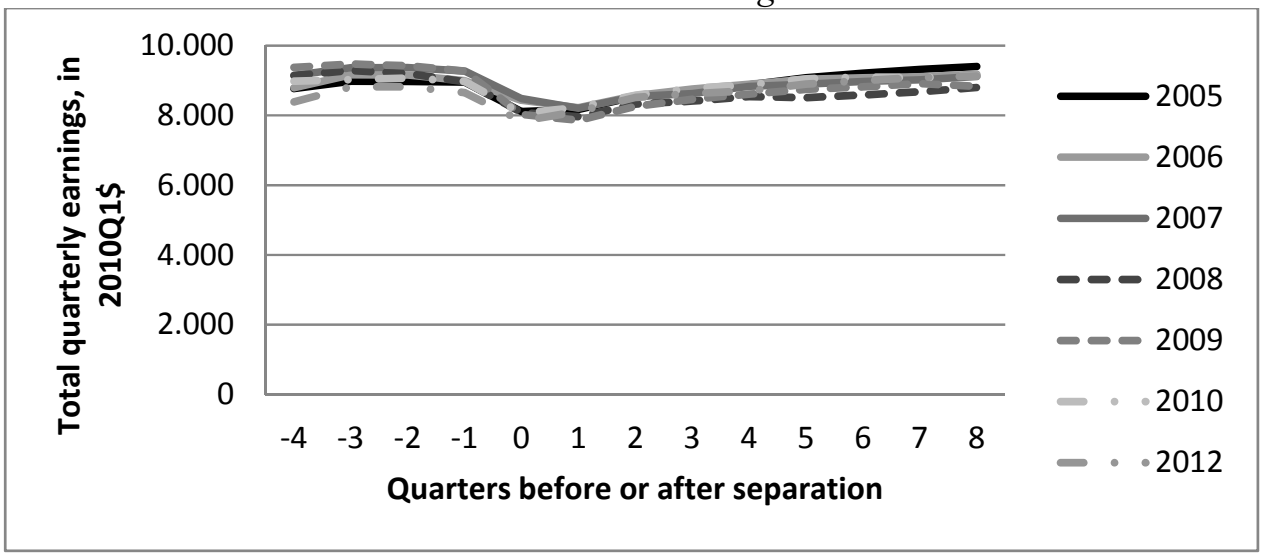

Notes: Calculations from LEHD. Earnings are in 2010Q1 dollars. Earnings are top-coded at the $99^{\text {th }}$ percentile for the displacement quarter and subsequent quarters. Employment status is defined as positive earnings during the quarter. 
Figure 3: Effects of networks ( $A E N$ ) on employment status in quarter following displacement, estimated interquartile effects and effects with network measures held fixed or network effects held fixed

Full sample

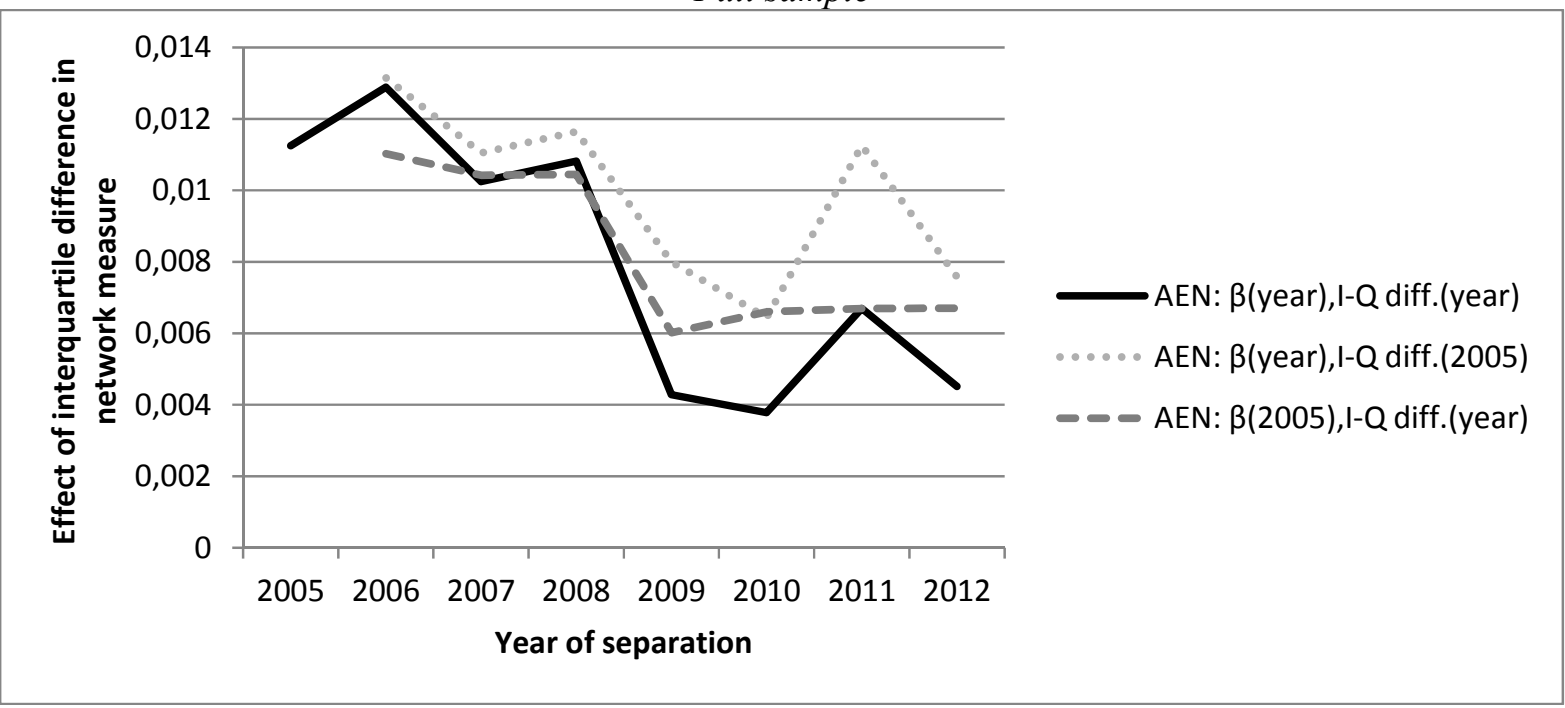

Low-earnings sample (pre-displacement earnings $<\$ 50,000)$

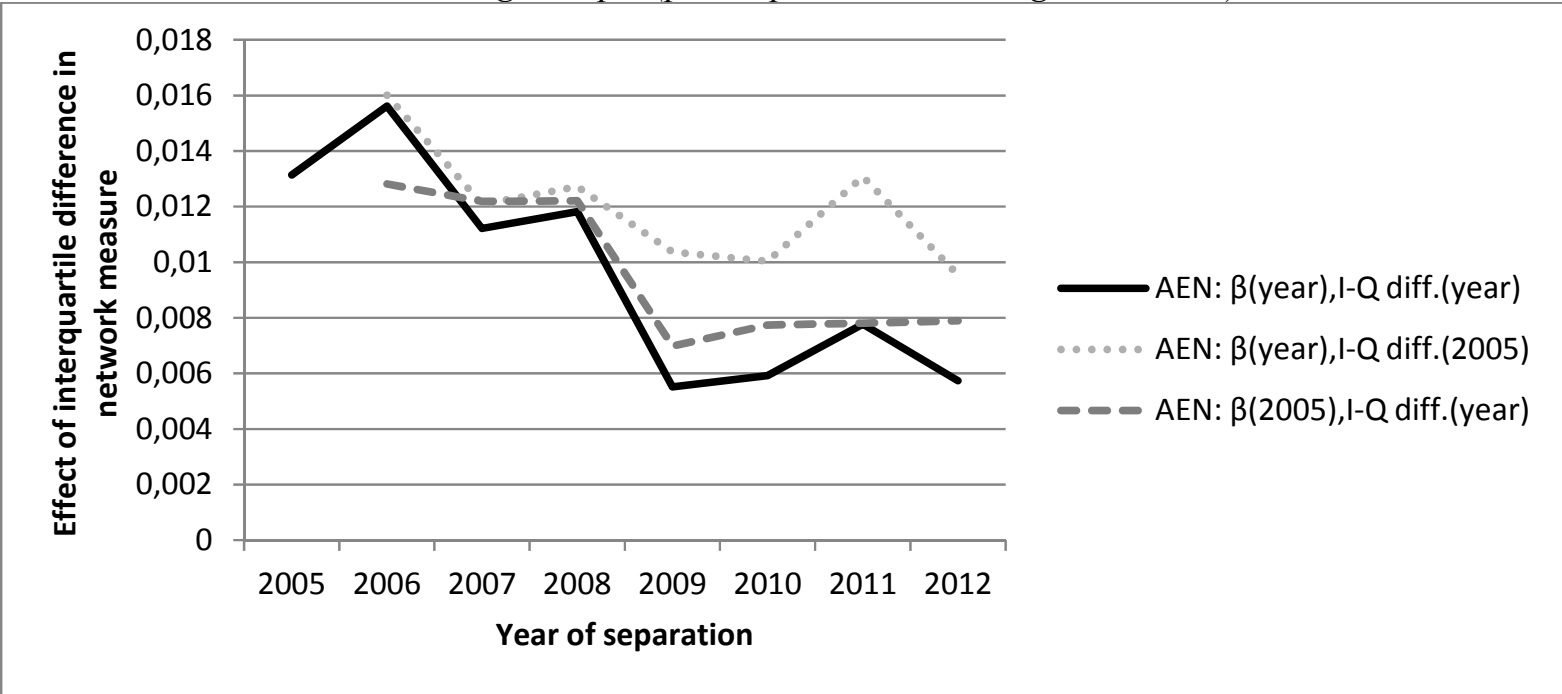

Notes: See notes to Table 4. "Estimated interquartile effects" are reported in the second panel of the table. "Network effects" are the estimated coefficients in the first panel of the table. In the two sets of hypothetical estimates, the network measures or network effects are held at their 2005 values. 
Figure 4: Effects of networks ( $A E N$ ) on employment at a neighbor's employer in quarter following displacement, estimated interquartile effects and effects with network measures held fixed or network effects held fixed

\section{Full sample}

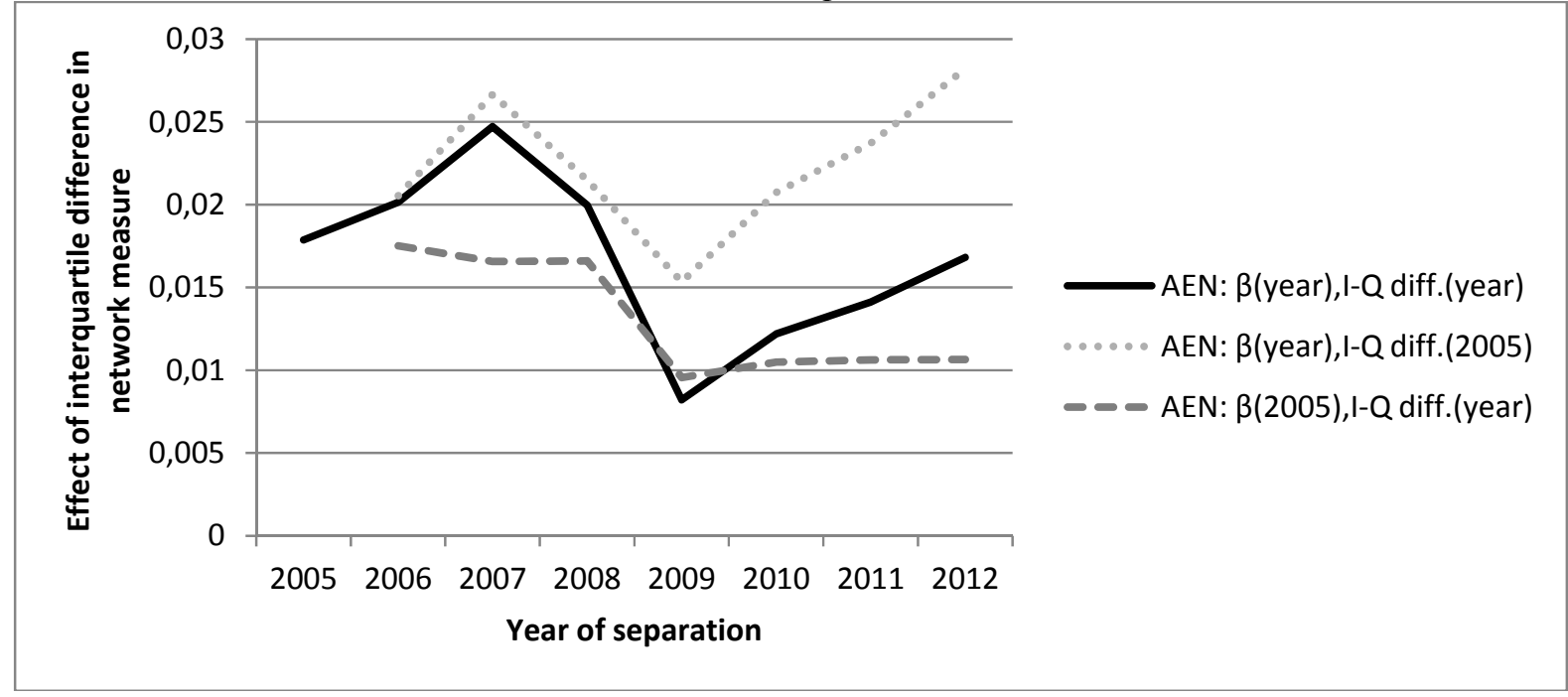

Low-earnings sample (pre-displacement earnings $<\$ 50,000$ )

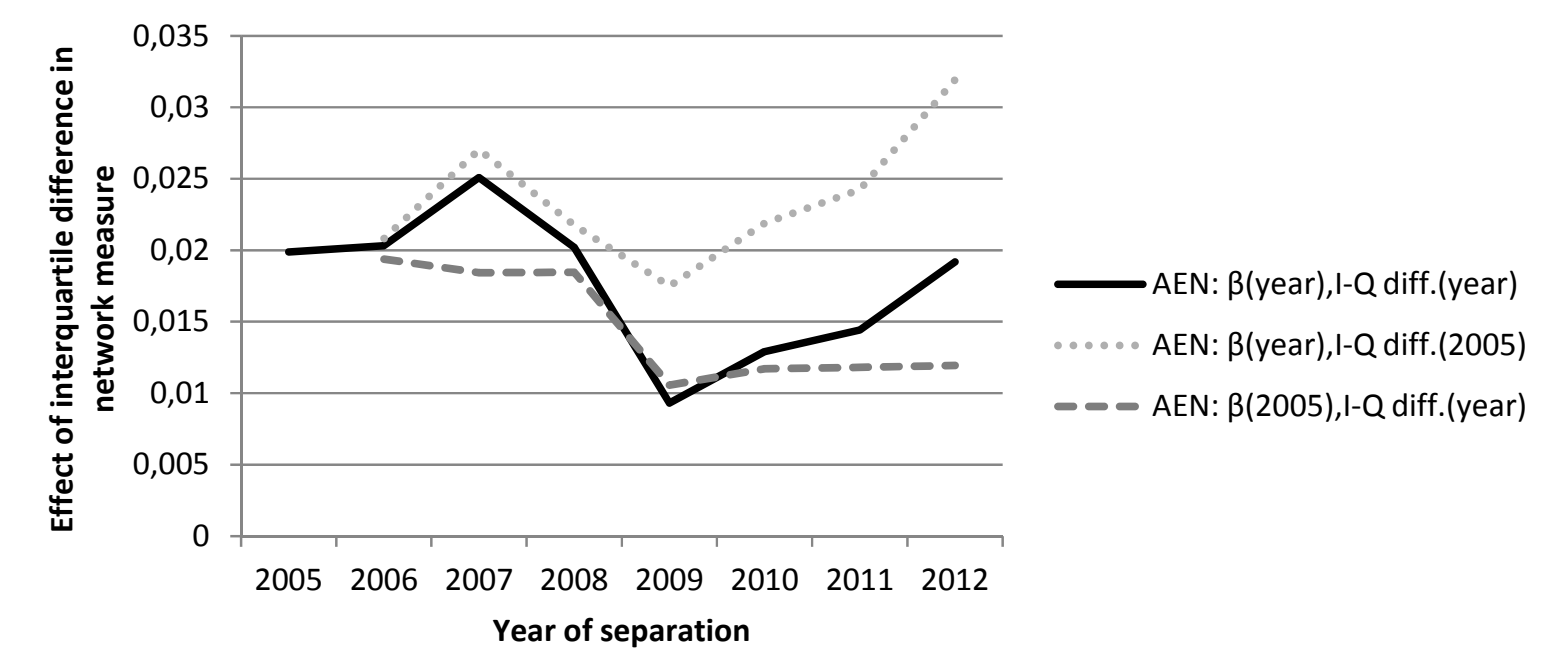

Notes: See Table 5 and notes to Figure 3. 
Figure 5: Effects of networks ( $A E N)$ on employment at a neighbor's employer in quarter following displacement, conditional on re-employment, estimated interquartile effects and effects with network measures held fixed or network effects held fixed
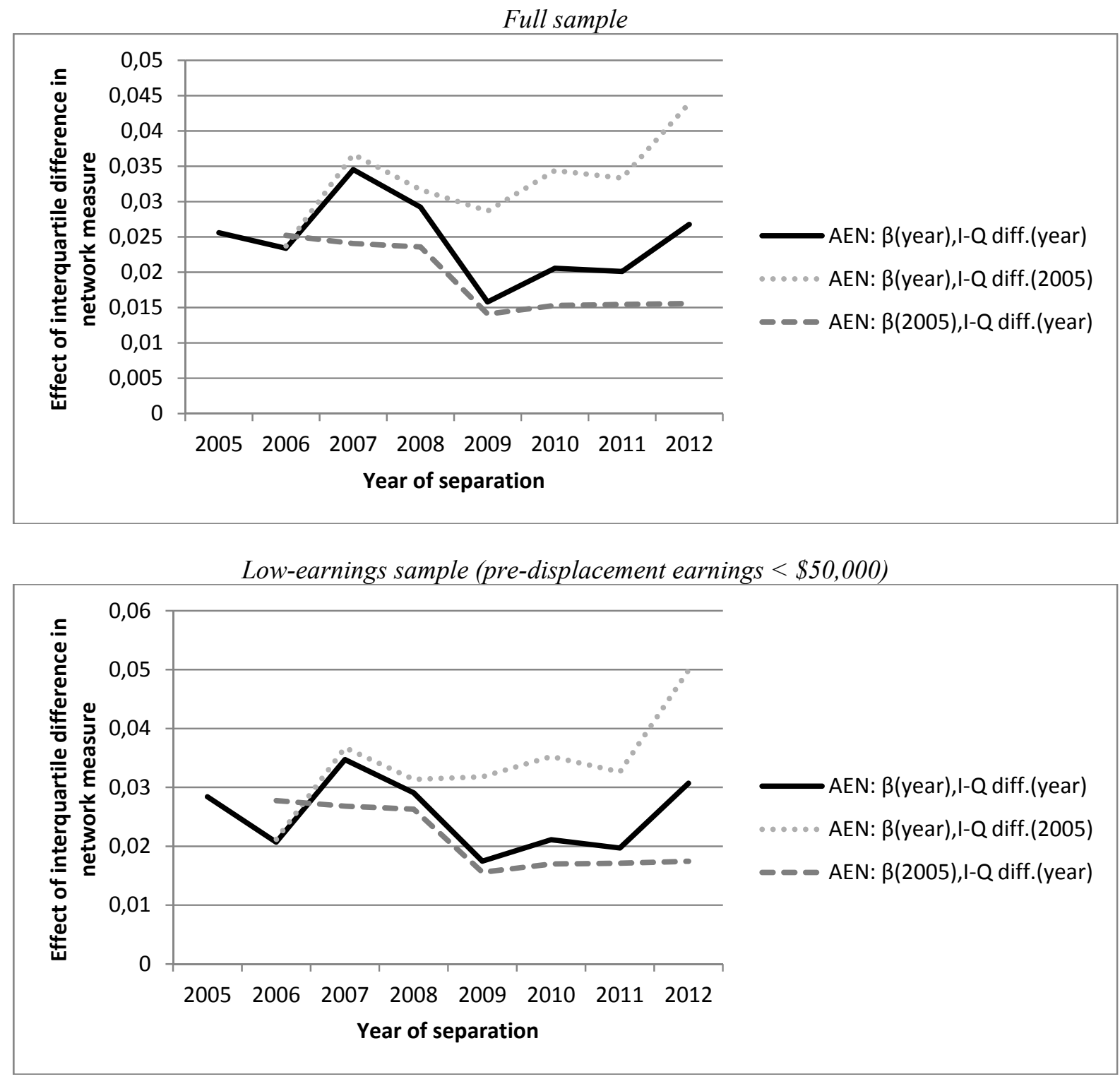

Notes: See Table 6 and notes to Figure 3. 
Table 1: Sample means

\begin{tabular}{|c|c|c|c|}
\hline Variable & Mean & Variable & Mean \\
\hline Employment indicator in quarter after displacement & 0.59 & Agriculture and mining $(11,21)$ & 0.01 \\
\hline Earnings in quarter after displacement $(1,000 \mathrm{~s} 2010 \mathrm{Q} 1 \$)$ & 4.84 & Utility, wholesale, transportation $(22,42,48-49)$ & 0.08 \\
\hline Share employed (layoff quarter) & 0.65 & Construction (23) & 0.10 \\
\hline Share in poverty rate in tract $(2000)$ & 0.13 & Manufacturing (31-33) & 0.12 \\
\hline Share in same house last year (2000) & 0.51 & Retail, administrative, other services $(44-45,56,81)$ & 0.26 \\
\hline Share foreign born (2000) & 0.16 & Professional services $(51-55)$ & 0.20 \\
\hline Share less than high school (2000) & 0.21 & Education, health, public $(61,62,92)$ & 0.13 \\
\hline Share some college (2000) & 0.28 & Local services $(71,72)$ & 0.11 \\
\hline Share college or more (2000) & 0.25 & Displaced in 2005 & 0.12 \\
\hline Share white, not Hispanic (2000) & 0.59 & Displaced in 2006 & 0.12 \\
\hline Share black, not Hispanic (2000) & 0.16 & Displaced in 2007 & 0.14 \\
\hline Earnings at employer in previous year $(1,000$ s $2010 \mathrm{Q} 1 \$)$ & 34.87 & Displaced in 2008 & 0.18 \\
\hline Earnings from other jobs in previous year $(1,000$ s $2010 \mathrm{Q} 1 \$)$ & 1.46 & Displaced in 2009 & 0.16 \\
\hline Age 19 to 24 & 0.14 & Displaced in 2010 & 0.11 \\
\hline Age 25 to 34 & 0.30 & Displaced in 2010 & 0.10 \\
\hline Age 35 to 44 & 0.23 & Displaced in 2012 & 0.08 \\
\hline Age 45 to 54 & 0.20 & Displaced in quarter 1 & 0.23 \\
\hline Age 55 to 64 & 0.13 & Displaced in quarter 2 & 0.26 \\
\hline Female & 0.46 & Displaced in quarter 3 & 0.26 \\
\hline Male & 0.54 & Displaced in quarter 4 & 0.25 \\
\hline White non-Hispanic & 0.53 & & \\
\hline Black non-Hispanic & 0.19 & & \\
\hline Other race non-Hispanic & 0.02 & & \\
\hline Asian non-Hispanic & 0.06 & & \\
\hline Hispanic & 0.20 & & \\
\hline Observations $(1,000 \mathrm{~s})$ & 9,195 & & \\
\hline
\end{tabular}

Notes: Calculations from LEHD data. NAICS industry sector code ranges are listed. 
Table 2: Longitudinal variation in sample

\begin{tabular}{|c|c|c|c|c|c|c|c|c|c|}
\hline $\begin{array}{l}\text { Displacement } \\
\text { (year) } \\
\text { (1) }\end{array}$ & $\begin{array}{c}\text { Observations } \\
(1,000 \mathrm{~s}) \\
(2)\end{array}$ & $\begin{array}{c}\text { Percent } \\
\text { sample } \\
\text { observations } \\
\text { (3) }\end{array}$ & $\begin{array}{c}\text { Layoff } \\
\text { events } \\
(1,000 \mathrm{~s}) \\
(4)\end{array}$ & $\begin{array}{l}\text { Percent } \\
\text { layoff } \\
\text { events } \\
(5)\end{array}$ & $\begin{array}{c}\text { Average } \\
\text { displaced } \\
\text { workers per } \\
\text { layoff event } \\
(6)\end{array}$ & $\begin{array}{c}\text { Average earnings } \\
\text { at displaced job } \\
\text { in previous year } \\
\text { (7) }\end{array}$ & $\begin{array}{c}\text { Average } \\
\text { earnings at } \\
\text { other jobs in } \\
\text { previous year } \\
\text { (8) }\end{array}$ & $\begin{array}{l}\text { Employment } \\
\text { rate in } \\
\text { quarter after } \\
\text { job loss } \\
\text { (9) }\end{array}$ & $\begin{array}{c}\text { Average } \\
\text { earnings in } \\
\text { quarter after } \\
\text { job loss } \\
(10)\end{array}$ \\
\hline 2005 & 1,126 & 12.2 & 247 & 11.9 & 102.9 & 34,175 & 1,492 & 0.633 & 5,260 \\
\hline 2006 & 1,086 & 11.8 & 254 & 12.3 & 91.3 & 34,474 & 1,626 & 0.647 & 5,423 \\
\hline 2007 & 1,248 & 13.6 & 283 & 13.7 & 82.7 & 35,549 & 1,602 & 0.633 & 5,288 \\
\hline 2008 & 1,620 & 17.6 & 365 & 17.6 & 75.4 & 35,061 & 1,540 & 0.569 & 4,614 \\
\hline 2009 & 1,504 & 16.4 & 331 & 16.0 & 61.0 & 36,162 & 1,383 & 0.479 & 3,835 \\
\hline 2010 & 978 & 10.6 & 223 & 10.8 & 96.5 & 34,760 & 1,292 & 0.553 & 4,650 \\
\hline 2011 & 946 & 10.3 & 209 & 10.1 & 96.6 & 34,120 & 1,297 & 0.594 & 5,026 \\
\hline 2012 & 686 & 7.5 & 159 & 7.7 & 49.9 & 33,347 & 1,333 & 0.618 & 5,106 \\
\hline All years & 9,195 & 100.0 & 2,072 & 100.0 & 81.8 & 34,873 & 1,460 & 0.585 & 4,836 \\
\hline
\end{tabular}

Notes: Calculations from LEHD data. Earnings are in 2010Q1 dollars. 


\begin{tabular}{|c|c|c|}
\hline Variable & $\begin{array}{l}\text { Employment in } \\
\text { quarter following } \\
\text { displacement } \\
\text { (1) }\end{array}$ & $\begin{array}{c}\text { Employment in quarter following } \\
\text { displacement, pre-displacement } \\
\text { earnings }<\$ 50,000 \\
(2) \\
\end{array}$ \\
\hline Active employer network ( $A E N)$ & $0.321 * * *$ & $0.364 * * *$ \\
\hline Active tract control $(A T C)$ & $0.142 * * *$ & $0.169 * * *$ \\
\hline Share employed (layoff quarter) & $0.219 * * *$ & $0.192 * * *$ \\
\hline Share in poverty rate in tract $(2000)$ & $0.014 * * *$ & $0.014 * * *$ \\
\hline Share in same house last year (2000) & $-0.032 * * *$ & $-0.030 * * *$ \\
\hline Share foreign born (2000) & -0.001 & $-0.006^{* *}$ \\
\hline Share less than high school (2000) & $-0.022 * * *$ & $-0.010^{*}$ \\
\hline Share some college (2000) & $0.026 * * *$ & $0.022 * * *$ \\
\hline Share college or more (2000) & $-0.014 * * *$ & -0.002 \\
\hline Share white, not Hispanic (2000) & $0.009 * * *$ & $0.012 * * *$ \\
\hline Share black, not Hispanic (2000) & $-0.004 * *$ & -0.002 \\
\hline Earnings $(\$ 1,000 \mathrm{~s})$ at employer in previous year & $0.002 * * *$ & $0.004 * * *$ \\
\hline Earnings $(\$ 1,000 \mathrm{~s})$ from other jobs in previous year & $0.016^{* * *}$ & $0.025 * * *$ \\
\hline Age 19 to 24 & $0.087 * * *$ & $0.096 * * *$ \\
\hline Age 25 to 34 & $0.040 * * *$ & $0.040 * * *$ \\
\hline Age 45 to 54 & $-0.041 * * *$ & $-0.039 * * *$ \\
\hline Age 55 to 64 & $-0.144 * * *$ & $-0.131 * * *$ \\
\hline Female & $-0.009 * * *$ & $-0.008 * * *$ \\
\hline Black non-Hispanic & $-0.011 * * *$ & $-0.010^{* * *}$ \\
\hline Other race non-Hispanic & $-0.009 * * *$ & $-0.009 * * *$ \\
\hline Asian non-Hispanic & $-0.017 * * *$ & $-0.022 * * *$ \\
\hline Hispanic & $-0.003 * * *$ & $-0.002 * * *$ \\
\hline Constant & $0.147 * * *$ & $0.276^{* * *}$ \\
\hline Employer/year/quarter/county fixed effects & Yes & Yes \\
\hline Number of fixed effects included $(1,000 \mathrm{~s})$ & 2,072 & 1,813 \\
\hline R-squared (within) & 0.048 & 0.049 \\
\hline Observations $(1,000 \mathrm{~s})$ & 9,195 & 7,025 \\
\hline Mean of dependent variable & 0.585 & 0.567 \\
\hline
\end{tabular}

Notes: Employment estimates are from linear probability model for an indicator of employment. All specifications include industry dummy variables (using the categories from Table 1), which can vary slightly within employer/year/quarter/county fixed effects for some multiple-establishment employers in more than one industry; the estimated coefficients were very small and generally insignificant, and are not reported. The establishment-level network measures are top-coded at the $99^{\text {th }}$ percentile. The omitted indicators for the variables reported in the table are for age 35 to 44, male, and white non-Hispanic. The share variables are proportions. Robust standard errors, clustered by employer/year/quarter/county, are computed. Standard errors are not reported here, given that nearly all of the estimated coefficients are statistically significant at the one-percent level. *** $\mathrm{p}<0.01, * * \mathrm{p}<0.05, * \mathrm{p}<0.1$ 
Table 4: Effects of networks on employment status in quarter following displacement

\begin{tabular}{|c|c|c|c|c|c|c|c|c|c|}
\hline Displacement years & $2005-2012$ & 2005 & 2006 & 2007 & 2008 & 2009 & 2010 & 2011 & 2012 \\
\hline Variable & $(1)$ & $(2)$ & (3) & $(4)$ & $(5)$ & $(6)$ & $(7)$ & $(8)$ & (9) \\
\hline \multicolumn{10}{|c|}{ Full sample } \\
\hline Active employer network ( $A E N)$ & $\begin{array}{c}0.321 * * * \\
(0.017)\end{array}$ & $\begin{array}{c}0.313 * * * \\
(0.044)\end{array}$ & $\begin{array}{c}0.366^{* * *} \\
(0.047)\end{array}$ & $\begin{array}{c}0.308^{* * *} * \\
(0.045)\end{array}$ & $\begin{array}{c}0.324 * * * \\
(0.043)\end{array}$ & $\begin{array}{c}0.223^{* * *} \\
(0.050)\end{array}$ & $\begin{array}{c}0.179 * * * \\
(0.057)\end{array}$ & $\begin{array}{c}0.313^{* * *} \\
(0.060)\end{array}$ & $\begin{array}{c}0.211 * * * \\
(0.069)\end{array}$ \\
\hline Active tract control $(A T C)$ & $\begin{array}{c}0.142 * * * \\
(0.028)\end{array}$ & $\begin{array}{c}0.161 * * \\
(0.066)\end{array}$ & $\begin{array}{l}-0.035 \\
(0.073)\end{array}$ & $\begin{array}{c}0.071 \\
(0.070)\end{array}$ & $\begin{array}{c}0.294 * * * \\
(0.072)\end{array}$ & $\begin{array}{c}0.383 * * * \\
(0.080)\end{array}$ & $\begin{array}{c}0.103 \\
(0.094)\end{array}$ & $\begin{array}{c}0.138 \\
(0.094)\end{array}$ & $\begin{array}{c}0.316^{* * *} \\
(0.107)\end{array}$ \\
\hline \multicolumn{10}{|l|}{ Interquartile effects } \\
\hline Active employer network ( $A E N$ ) & 0.0115 & 0.0112 & 0.0129 & 0.0102 & 0.0108 & 0.0043 & 0.0038 & 0.0067 & 0.0045 \\
\hline Active tract control $(A T C)$ & 0.0045 & 0.0051 & -0.0011 & 0.0020 & 0.0089 & 0.0061 & 0.0019 & 0.0026 & 0.0058 \\
\hline Number of fixed effects included $(1,000 \mathrm{~s})$ & 2,072 & 247 & 254 & 283 & 365 & 331 & 223 & 209 & 159 \\
\hline R-squared (within) & 0.048 & 0.046 & 0.044 & 0.045 & 0.051 & 0.055 & 0.052 & 0.049 & 0.047 \\
\hline Observations $(1,000 \mathrm{~s})$ & 9,195 & 1,126 & 1,086 & 1,248 & 1,620 & 1,504 & 968 & 946 & 686 \\
\hline \multicolumn{10}{|c|}{ Low-earnings sample (pre-displacement earnings $<\$ 50,000)$} \\
\hline Active employer network ( $A E N)$ & $\begin{array}{c}0.364 * * * \\
(0.020)\end{array}$ & $\begin{array}{c}0.360 * * * \\
(0.050)\end{array}$ & $\begin{array}{c}0.439 * * * \\
(0.055)\end{array}$ & $\begin{array}{c}0.331 * * * \\
(0.054)\end{array}$ & $\begin{array}{c}0.349 * * * \\
(0.051)\end{array}$ & $\begin{array}{c}0.284 * * * \\
(0.058)\end{array}$ & $\begin{array}{c}0.275^{* * *} \\
(0.067)\end{array}$ & $\begin{array}{c}0.359 * * * \\
(0.069)\end{array}$ & $\begin{array}{c}0.262 * * * \\
(0.079)\end{array}$ \\
\hline Active tract control $(A T C)$ & $\begin{array}{c}0.169 * * * \\
(0.032)\end{array}$ & $\begin{array}{c}0.180 * * \\
(0.077)\end{array}$ & $\begin{array}{l}-0.059 \\
(0.083) \\
\end{array}$ & $\begin{array}{c}0.108 \\
(0.083) \\
\end{array}$ & $\begin{array}{c}0.351 * * * \\
(0.086)\end{array}$ & $\begin{array}{c}0.419 * * * \\
(0.095)\end{array}$ & $\begin{array}{c}0.078 \\
(0.112) \\
\end{array}$ & $\begin{array}{c}0.174 \\
(0.111) \\
\end{array}$ & $\begin{array}{c}0.403 * * * \\
(0.125)\end{array}$ \\
\hline \multicolumn{10}{|l|}{ Interquartile effects } \\
\hline Active employer network $(A E N)$ & 0.0134 & 0.0131 & 0.0156 & 0.0112 & 0.0118 & 0.0055 & 0.0059 & 0.0078 & 0.0057 \\
\hline Active tract control $(A T C)$ & 0.0055 & 0.0058 & -0.0018 & 0.0031 & 0.0106 & 0.0067 & 0.0014 & 0.0033 & 0.0075 \\
\hline Observations $(1,000 \mathrm{~s})$ & 7,025 & 873 & 835 & 942 & 1,237 & 1,125 & 746 & 730 & 536 \\
\hline \multicolumn{10}{|c|}{ High-earnings sample (pre-displacement earnings $\geq \$ 50,000)$} \\
\hline Active employer network $(A E N)$ & $\begin{array}{c}0.055 \\
(0.037)\end{array}$ & $\begin{array}{c}0.077 \\
(0.097)\end{array}$ & $\begin{array}{c}0.076 \\
(0.103)\end{array}$ & $\begin{array}{c}0.126 \\
(0.094)\end{array}$ & $\begin{array}{c}0.103 \\
(0.092)\end{array}$ & $\begin{array}{l}-0.009 \\
(0.106)\end{array}$ & $\begin{array}{l}-0.173 \\
(0.112)\end{array}$ & $\begin{array}{c}0.053 \\
(0.127)\end{array}$ & $\begin{array}{l}-0.044 \\
(0.151)\end{array}$ \\
\hline Active tract control $(A T C)$ & $\begin{array}{c}0.082 \\
(0.058) \\
\end{array}$ & $\begin{array}{l}-0.043 \\
(0.140)\end{array}$ & $\begin{array}{c}0.098 \\
(0.165) \\
\end{array}$ & $\begin{array}{c}0.007 \\
(0.143)\end{array}$ & $\begin{array}{c}0.269 * \\
(0.144)\end{array}$ & $\begin{array}{c}0.169 \\
(0.158) \\
\end{array}$ & $\begin{array}{c}0.248 \\
(0.189) \\
\end{array}$ & $\begin{array}{l}-0.055 \\
(0.190)\end{array}$ & $\begin{array}{l}-0.112 \\
(0.225)\end{array}$ \\
\hline \multicolumn{10}{|l|}{ Interquartile effects } \\
\hline Active employer network $(A E N)$ & 0.0018 & 0.0025 & 0.0024 & 0.0037 & 0.0032 & -0.0002 & -0.0034 & 0.0011 & -0.0008 \\
\hline Active tract network $(A T C)$ & 0.0025 & -0.0013 & 0.0029 & 0.0002 & 0.0081 & 0.0027 & 0.0043 & -0.0011 & -0.0019 \\
\hline Observations $(1,000 \mathrm{~s})$ & 2,170 & 253 & 251 & 306 & 383 & 380 & 232 & 216 & 150 \\
\hline
\end{tabular}

Notes: All specifications include employer/year/quarter/county fixed effects, and the worker control variables and Census tract control variables listed in Table 3. Robust standard errors in parentheses, clustered by employer/year/quarter/county. $* * * p<0.01,{ }^{* *} \mathrm{p}<0.05,{ }^{*} \mathrm{p}<0.1$. Employment estimates are from linear probability model for an indicator of employment. The establishment-level network measures are top-coded at the $99^{\text {th }}$ percentile. 
Table 5: Effects of networks on employment at a neighbor's employer in quarter following displacement

\begin{tabular}{|c|c|c|c|c|c|c|c|c|c|}
\hline Displacement years & $2005-2012$ & 2005 & 2006 & 2007 & 2008 & 2009 & 2010 & 2011 & 2012 \\
\hline Variable & (1) & (2) & (3) & (4) & $(5)$ & (6) & (7) & (8) & (9) \\
\hline \multicolumn{10}{|c|}{ Full sample } \\
\hline Active employer network ( $A E N)$ & $\begin{array}{c}0.575 * * * \\
(0.021)\end{array}$ & $\begin{array}{c}0.497 * * * \\
(0.045)\end{array}$ & $\begin{array}{c}0.572 * * * \\
(0.054)\end{array}$ & $\begin{array}{c}0.742 * * * \\
(0.055)\end{array}$ & $\begin{array}{c}0.598 * * * \\
(0.075)\end{array}$ & $\begin{array}{c}0.427 * * * \\
(0.042)\end{array}$ & $\begin{array}{c}0.577 * * * \\
(0.065)\end{array}$ & $\begin{array}{c}0.660 * * * \\
(0.056)\end{array}$ & $\begin{array}{c}0.785 * * * \\
(0.092)\end{array}$ \\
\hline Active tract control $(A T C)$ & $\begin{array}{c}0.324 * * * \\
(0.032)\end{array}$ & $\begin{array}{c}0.288 * * * \\
(0.069)\end{array}$ & $\begin{array}{c}0.203 \\
(0.123) \\
\end{array}$ & $\begin{array}{c}0.138 * * \\
(0.069)\end{array}$ & $\begin{array}{c}0.391^{* * *} \\
(0.076)\end{array}$ & $\begin{array}{c}0.378 * * * \\
(0.068)\end{array}$ & $\begin{array}{c}0.410 * * * \\
(0.096)\end{array}$ & $\begin{array}{c}0.262 * * * \\
(0.099)\end{array}$ & $\begin{array}{c}0.504 * * * \\
(0.114)\end{array}$ \\
\hline \multicolumn{10}{|l|}{ Interquartile effects } \\
\hline Active employer network $(A E N)$ & 0.0206 & 0.0179 & 0.0201 & 0.0247 & 0.0200 & 0.0082 & 0.0122 & 0.0141 & 0.0168 \\
\hline Active tract control $(A T C)$ & 0.0103 & 0.0092 & 0.0062 & 0.0040 & 0.0118 & 0.0060 & 0.0074 & 0.0050 & 0.0092 \\
\hline Number of fixed effects included $(1,000 \mathrm{~s})$ & 2,072 & 247 & 254 & 283 & 365 & 331 & 223 & 209 & 159 \\
\hline R-squared (within) & 0.008 & 0.009 & 0.009 & 0.008 & 0.008 & 0.007 & 0.007 & 0.007 & 0.008 \\
\hline Observations $(1,000 \mathrm{~s})$ & 9,195 & 1,126 & 1,086 & 1,248 & 1,620 & 1,504 & 968 & 946 & 686 \\
\hline \multicolumn{10}{|c|}{ Low-earnings sample (pre-displacement earnings $<\$ 50,000)$} \\
\hline Active employer network $(A E N)$ & $\begin{array}{c}0.590 * * * \\
(0.021)\end{array}$ & $\begin{array}{c}0.545^{* * *} \\
(0.050)\end{array}$ & $\begin{array}{c}0.571 * * * \\
(0.056)\end{array}$ & $\begin{array}{c}0.741 * * * \\
(0.055)\end{array}$ & $\begin{array}{c}0.596 * * * \\
(0.066)\end{array}$ & $\begin{array}{c}0.480 * * * \\
(0.048)\end{array}$ & $\begin{array}{c}0.600 * * * \\
(0.059)\end{array}$ & $\begin{array}{c}0.665^{* * *} \\
(0.064)\end{array}$ & $\begin{array}{c}0.875 * * * \\
(0.105)\end{array}$ \\
\hline Active tract control $(A T N)$ & $\begin{array}{c}0.368 * * * \\
(0.032)\end{array}$ & $\begin{array}{c}0.251 * * * \\
(0.077)\end{array}$ & $\begin{array}{c}0.338 * * * \\
(0.088)\end{array}$ & $\begin{array}{c}0.177 * * \\
(0.081)\end{array}$ & $\begin{array}{c}0.381 * * * \\
(0.081)\end{array}$ & $\begin{array}{c}0.442 * * * \\
(0.079)\end{array}$ & $\begin{array}{c}0.368 * * * \\
(0.116)\end{array}$ & $\begin{array}{c}0.372 * * * \\
(0.103)\end{array}$ & $\begin{array}{c}0.593 * * * \\
(0.136)\end{array}$ \\
\hline \multicolumn{10}{|l|}{ Interquartile effects } \\
\hline Active employer network $(A E N)$ & 0.0217 & 0.0199 & 0.0203 & 0.0251 & 0.0202 & 0.0093 & 0.0129 & 0.0144 & 0.0192 \\
\hline Active tract control $(A T N)$ & 0.0119 & 0.0081 & 0.0104 & 0.0051 & 0.0115 & 0.0070 & 0.0067 & 0.0071 & 0.0111 \\
\hline Observations $(1,000 \mathrm{~s})$ & 7,025 & 873 & 835 & 942 & 1,237 & 1,125 & 746 & 730 & 536 \\
\hline
\end{tabular}

Notes: All specifications include employer/year/quarter/county fixed effects, and the worker control variables and Census tract control variables listed in Table 3 . Robust standard errors in parentheses, clustered by employer/year/quarter/county. $* * * p<0.01, * * p<0.05, * p<0.1$. Employment estimates are from linear probability model for an indicator of employment. The establishment-level network measures are top-coded at the $99^{\text {th }}$ percentile. 
Table 6: Effects of networks on employment at a neighbor's employer in quarter following displacement, conditional on re-employment

\begin{tabular}{|c|c|c|c|c|c|c|c|c|c|}
\hline Displacement years & $2005-2012$ & 2005 & 2006 & 2007 & 2008 & 2009 & 2010 & 2011 & 2012 \\
\hline Variable & $(1)$ & $(2)$ & $(3)$ & $(4)$ & $(5)$ & $(6)$ & $(7)$ & $(8)$ & $(9)$ \\
\hline \multicolumn{10}{|c|}{ Full sample } \\
\hline Active employer network ( $A E N)$ & $\begin{array}{c}0.822 * * * \\
(0.036)\end{array}$ & $\begin{array}{c}0.716^{* * *} \\
(0.067)\end{array}$ & $\begin{array}{c}0.663 * * * \\
(0.083)\end{array}$ & $\begin{array}{c}1.026^{* * *} \\
(0.088)\end{array}$ & $\begin{array}{c}0.886^{* * *} \\
(0.134)\end{array}$ & $\begin{array}{c}0.802 * * * \\
(0.085)\end{array}$ & $\begin{array}{c}0.962 * * * \\
(0.115)\end{array}$ & $\begin{array}{c}0.932 * * * \\
(0.089)\end{array}$ & $\begin{array}{c}1.229 * * * \\
(0.150)\end{array}$ \\
\hline Active tract control $(A T C)$ & $\begin{array}{c}0.385^{* * *} * \\
(0.054)\end{array}$ & $\begin{array}{c}0.397 * * * \\
(0.108)\end{array}$ & $\begin{array}{c}0.304 \\
(0.195)\end{array}$ & $\begin{array}{c}0.131 \\
(0.105)\end{array}$ & $\begin{array}{c}0.406^{* * *} \\
(0.127)\end{array}$ & $\begin{array}{c}0.369^{* * *} * \\
(0.135)\end{array}$ & $\begin{array}{c}0.658 * * * \\
(0.164)\end{array}$ & $\begin{array}{c}0.317 * * \\
(0.161)\end{array}$ & $\begin{array}{c}0.525 * * * \\
(0.174)\end{array}$ \\
\hline \multicolumn{10}{|l|}{ Interquartile effects } \\
\hline Active employer network ( $A E N)$ & 0.0302 & 0.0256 & 0.0234 & 0.0345 & 0.0292 & 0.0158 & 0.0206 & 0.0201 & 0.0268 \\
\hline Active tract control $(A T C)$ & 0.0126 & 0.0125 & 0.0093 & 0.0038 & 0.0117 & 0.0060 & 0.0120 & 0.0060 & 0.0096 \\
\hline Number of fixed effects included $(1,000 \mathrm{~s})$ & 1,611 & 203 & 209 & 232 & 282 & 230 & 166 & 162 & 127 \\
\hline R-squared (within) & 0.012 & 0.013 & 0.014 & 0.013 & 0.013 & 0.012 & 0.011 & 0.010 & 0.011 \\
\hline Observations $(1,000 \mathrm{~s})$ & 5,377 & 713 & 703 & 790 & 922 & 721 & 541 & 562 & 424 \\
\hline \multicolumn{10}{|c|}{ Low-earnings sample (pre-displacement earnings $<\$ 50,000)$} \\
\hline Active employer network $(A E N)$ & $\begin{array}{c}0.813 * * * \\
(0.036)\end{array}$ & $\begin{array}{c}0.783 * * * \\
(0.077)\end{array}$ & $\begin{array}{c}0.584 * * * \\
(0.084)\end{array}$ & $\begin{array}{c}1.014 * * * \\
(0.085)\end{array}$ & $\begin{array}{c}0.865 * * * \\
(0.118)\end{array}$ & $\begin{array}{c}0.877 * * * \\
(0.100)\end{array}$ & $\begin{array}{c}0.972 * * * \\
(0.106)\end{array}$ & $\begin{array}{c}0.900 * * * \\
(0.105)\end{array}$ & $\begin{array}{c}1.377 * * * \\
(0.176)\end{array}$ \\
\hline Active tract control $(A T C)$ & $\begin{array}{c}0.464 * * * \\
(0.053)\end{array}$ & $\begin{array}{c}0.363 * * * \\
(0.122)\end{array}$ & $\begin{array}{c}0.547 * * * \\
(0.134)\end{array}$ & $\begin{array}{c}0.166 \\
(0.125) \\
\end{array}$ & $\begin{array}{c}0.357 * * * \\
(0.137)\end{array}$ & $\begin{array}{c}0.482 * * * \\
(0.160)\end{array}$ & $\begin{array}{c}0.609 * * * \\
(0.204)\end{array}$ & $\begin{array}{c}0.529 * * * \\
(0.167)\end{array}$ & $\begin{array}{c}0.596 * * * \\
(0.214)\end{array}$ \\
\hline \multicolumn{10}{|l|}{ Interquartile effects } \\
\hline Active employer network $(A E N)$ & 0.0309 & 0.0284 & 0.0207 & 0.0347 & 0.0291 & 0.0175 & 0.0211 & 0.0197 & 0.0307 \\
\hline Active tract control $(A T C)$ & 0.0155 & 0.0117 & 0.0168 & 0.0048 & 0.0103 & 0.0078 & 0.0112 & 0.0100 & 0.0112 \\
\hline Observations $(1,000 \mathrm{~s})$ & 3,983 & 539 & 529 & 583 & 679 & 515 & 398 & 418 & 323 \\
\hline
\end{tabular}

Notes: All specifications include employer/year/quarter/county fixed effects, and the worker control variables and Census tract control variables listed in Table 3. Robust standard errors in parentheses, clustered by employer/year/quarter/county. ${ }^{* *} \mathrm{p}<0.01, * * \mathrm{p}<0.05,{ }^{*} \mathrm{p}<0.1$. Employment estimates are from linear probability model for an indicator of employment. The establishment-level network measures are top-coded at the $99^{\text {th }}$ percentile. 
Table 7: Effects of network on employment at a neighbor's employer in quarter following displacement, conditional on re-employment, pooled years 2005-2011, different controls

\begin{tabular}{|c|c|c|c|c|c|c|c|c|}
\hline & \multicolumn{2}{|c|}{ All controls (Table 6) } & $\begin{array}{r}\text { Employer/ } \\
\text { fixe } \\
\text { Full } \\
\text { sample }\end{array}$ & $\begin{array}{l}\text { ear/quarter/county } \\
\text { effects only } \\
\text { Pre-displacement } \\
\text { earnings } \\
<\$ 50,000\end{array}$ & Fixed e & $\begin{array}{l}\text { fects }+ \text { worker } \\
\text { ontrols } \\
\text { Pre-displacement } \\
\text { earnings } \\
\quad<\$ 50,000\end{array}$ & Fixed effe & $\begin{array}{l}\mathrm{s}+\text { neighborhood } \\
\text { ontrols } \\
\text { Pre-displacement } \\
\text { earnings } \\
<\$ 50,000\end{array}$ \\
\hline Variable & (1) & (2) & (3) & (4) & (5) & (6) & (7) & (8) \\
\hline Active employer network ( $A E N)$ & $\begin{array}{c}0.822 * * * \\
(0.036)\end{array}$ & $\begin{array}{c}0.813 * * * \\
(0.036)\end{array}$ & $\begin{array}{c}0.821 * * * \\
(0.026)\end{array}$ & $\begin{array}{c}0.932 * * * \\
(0.028)\end{array}$ & $\begin{array}{c}0.475 * * * \\
(0.027)\end{array}$ & $\begin{array}{c}0.662 * * * \\
(0.028)\end{array}$ & $\begin{array}{c}0.889 * * * \\
(0.035)\end{array}$ & $\begin{array}{c}0.844 * * * \\
(0.036)\end{array}$ \\
\hline Active tract control (ATC) & $\begin{array}{c}0.385 * * * \\
(0.054)\end{array}$ & $\begin{array}{c}0.464 * * * \\
(0.053)\end{array}$ & $\begin{array}{c}1.063 * * * \\
(0.041)\end{array}$ & $\begin{array}{c}1.162 * * * \\
(0.040)\end{array}$ & $\begin{array}{c}1.480 * * * \\
(0.042)\end{array}$ & $\begin{array}{c}1.566^{* * * *} \\
(0.040)\end{array}$ & $\begin{array}{c}0.365 * * * \\
(0.054)\end{array}$ & $\begin{array}{c}0.455 * * * \\
(0.053)\end{array}$ \\
\hline Interquartile effects & & & & & & & & \\
\hline Active employer network ( $A E N)$ & 0.0302 & 0.0309 & 0.0302 & 0.0354 & 0.0175 & 0.0251 & 0.0327 & 0.0320 \\
\hline Active tract control $(A T C)$ & 0.0126 & 0.0155 & 0.0346 & 0.0387 & 0.0482 & 0.0522 & 0.0119 & 0.0151 \\
\hline R-squared (within) & 0.012 & 0.013 & 0.002 & 0.002 & 0.011 & 0.012 & 0.003 & 0.003 \\
\hline
\end{tabular}

Notes: All specifications include employer/year/quarter/county fixed effects, and the worker control variables and Census tract control variables listed in Table 3, as indicated in the column headings (the industry dummy variables are worker controls). Robust standard errors in parentheses, clustered by

employer/year/quarter/county. $* * * p<0.01, * * p<0.05, * p<0.1$. Employment estimates are from linear probability model for an indicator of employment. The

establishment-level network measures are top-coded at the $99^{\text {th }}$ percentile. 
Table 8: Effects of alternative network measures on different employment outcomes in quarter following displacement, pooled years 2005-2012

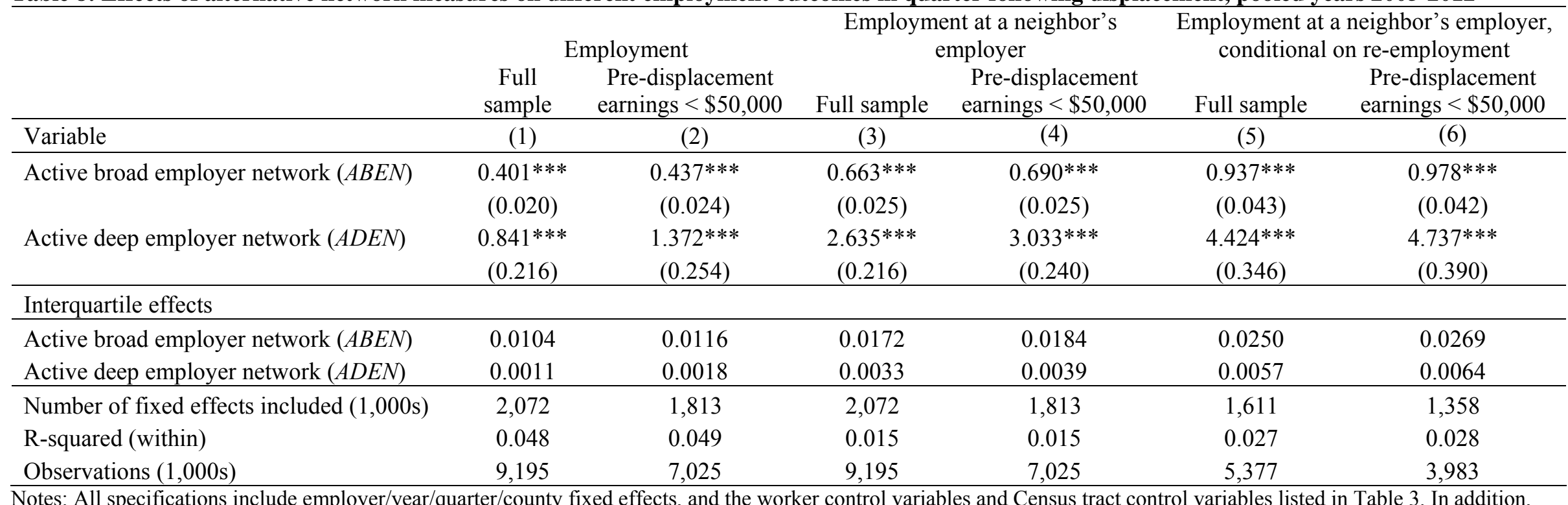

Notes: All specifications include employer/year/quarter/county fixed effects, and the worker control variables and Census tract control variables listed in Table 3. In addition,

the specifications include the active tract hiring controls $A B T N$ and $A D T N$. Robust standard errors in parentheses, clustered by employer/year/quarter/county, *** $<<0.01, * *$

$\mathrm{p}<0.05, * \mathrm{p}<0.1$. Employment estimates are from linear probability model for an indicator of employment. The establishment-level network measures are top-coded at the

$99^{\text {th }}$ percentile. 
Table A1: Sample composition by year

\begin{tabular}{|c|c|c|c|c|c|c|c|c|c|}
\hline Displacement year & 2005 & 2006 & 2007 & 2008 & 2009 & 2010 & 2011 & 2012 & All \\
\hline \multicolumn{10}{|l|}{ Variable } \\
\hline \multicolumn{10}{|l|}{ Sex } \\
\hline Male & 50.9 & 52.6 & 53.0 & 56.4 & 57.7 & 53.0 & 52.3 & 52.4 & 54.0 \\
\hline Female & 49.1 & 47.4 & 47.0 & 43.6 & 42.3 & 47.0 & 47.7 & 47.7 & 46.1 \\
\hline \multicolumn{10}{|l|}{ Age } \\
\hline 19 to 24 & 16.0 & 15.9 & 14.9 & 14.3 & 12.9 & 13.6 & 13.5 & 13.9 & 14.3 \\
\hline 25 to 34 & 29.6 & 29.6 & 30.0 & 29.6 & 28.9 & 30.0 & 30.2 & 30.2 & 29.7 \\
\hline 35 to 45 & 24.1 & 23.8 & 23.5 & 23.3 & 23.1 & 22.5 & 22.2 & 22.2 & 23.2 \\
\hline 45 to 54 & 19.4 & 19.6 & 19.9 & 20.6 & 21.5 & 20.7 & 20.5 & 20.1 & 20.4 \\
\hline 55 to 64 & 10.9 & 11.2 & 11.6 & 12.3 & 13.6 & 13.3 & 13.7 & 13.7 & 12.5 \\
\hline \multicolumn{10}{|l|}{ Race/ethnicity } \\
\hline White non-Hispanic & 52.9 & 53.1 & 53.8 & 53.0 & 53.3 & 53.7 & 53.1 & 52.9 & 53.2 \\
\hline Black non-Hispanic & 21.0 & 19.4 & 18.4 & 18.6 & 17.8 & 18.7 & 19.2 & 19.3 & 19.0 \\
\hline Other race non-Hispanic & 1.6 & 1.6 & 1.6 & 1.7 & 1.6 & 1.7 & 1.7 & 1.7 & 1.7 \\
\hline Asian non-Hispanic & 5.8 & 5.5 & 5.6 & 5.9 & 6.2 & 5.7 & 5.6 & 5.4 & 5.8 \\
\hline Hispanic & 18.7 & 20.3 & 20.6 & 20.9 & 21.0 & 20.2 & 20.5 & 20.7 & 20.4 \\
\hline \multicolumn{10}{|l|}{ Industry (NAICS sectors) } \\
\hline Agriculture and mining & 0.7 & 0.7 & 0.6 & 0.7 & 1.0 & 0.8 & 0.8 & 1.1 & 0.8 \\
\hline Utility, wholesale, transportation & 8.2 & 8.3 & 7.4 & 8.5 & 9.2 & 8.3 & 8.3 & 8.1 & 8.3 \\
\hline Construction & 7.0 & 8.6 & 10.6 & 11.2 & 11.4 & 9.6 & 8.3 & 7.4 & 9.6 \\
\hline Manufacturing & 11.7 & 11.9 & 12.2 & 14.3 & 15.6 & 9.6 & 8.2 & 9.0 & 12.1 \\
\hline Retail, administrative, other services & 26.7 & 26.8 & 24.8 & 28.0 & 25.0 & 23.8 & 25.4 & 24.8 & 25.8 \\
\hline Professional services & 18.7 & 19.8 & 21.5 & 19.1 & 20.2 & 20.8 & 19.9 & 18.9 & 19.9 \\
\hline Education, health, public & 14.8 & 12.7 & 12.7 & 9.2 & 9.2 & 14.8 & 16.9 & 17.1 & 12.8 \\
\hline Local services & 12.2 & 11.3 & 10.2 & 9.0 & 8.4 & 12.4 & 12.2 & 13.6 & 10.7 \\
\hline \multicolumn{10}{|l|}{ Previous year earnings (2010Q1\$) } \\
\hline$<\$ 25,000$ & 37.9 & 36.9 & 34.4 & 35.7 & 34.0 & 38.2 & 39.8 & 41.2 & 36.8 \\
\hline$\$ 25,000$ to $\$ 50,000$ & 39.7 & 40.0 & 41.1 & 40.6 & 40.8 & 38.1 & 37.4 & 37.0 & 39.6 \\
\hline$\$ 50,000$ to $\$ 75,000$ & 15.7 & 16.3 & 17.1 & 16.5 & 17.4 & 16.1 & 15.6 & 15.1 & 16.4 \\
\hline$>\$ 75,000$ & 6.8 & 6.9 & 7.4 & 7.2 & 7.9 & 7.6 & 7.3 & 6.8 & 7.3 \\
\hline Sample (thousands) & 1,126 & 1,086 & 1,248 & 1,620 & 1,504 & 978 & 946 & 686 & 9,195 \\
\hline Sample share & 12.25 & 11.81 & 13.57 & 17.62 & 16.36 & 10.64 & 10.29 & 7.46 & 100.00 \\
\hline
\end{tabular}

Notes: Calculations from LEHD data. See Table 1 notes for NAICS industry code ranges. 